Article

\title{
Populus euphratica JRL Mediates ABA Response, Ionic and ROS Homeostasis in Arabidopsis under Salt Stress
}

\author{
Huilong Zhang ${ }^{1,+}+\mathbb{0}$, Chen Deng ${ }^{1,+}$, Jun Yao ${ }^{1,+}$, Yan-Li Zhang ${ }^{1,+}$, Yi-Nan Zhang ${ }^{1}$, \\ Shurong Deng ${ }^{1,2}$, Nan Zhao ${ }^{1}$, Gang Sa ${ }^{1}$, Xiaoyang Zhou ${ }^{1}$, Cunfu Lu ${ }^{1}$, Shanzhi Lin ${ }^{1}$, \\ Rui Zhao ${ }^{1, *}$ and Shaoliang Chen ${ }^{1, *(D)}$ \\ 1 Beijing Advanced Innovation Center for Tree Breeding by Molecular Design, College of Biological Sciences \\ and Technology, Beijing Forestry University, Beijing 100083, China; hlzhang2018@126.com (H.Z.); \\ ced501@163.com (C.D.); yaojun@bjfu.edu.cn (J.Y.); z585788@163.com (Y.-L.Z.); xhzyn007@163.com (Y.-N.Z.); \\ danceon@126.com (S.D.); zhaonan19880921@126.com (N.Z.); sg_1214@126.com (G.S.); \\ zhouxiaoyang@bjfu.edu.cn (X.Z.); lucunfu@bjfu.edu.cn (C.L.); szlin@bjfu.edu.cn (S.L.) \\ 2 State Key Laboratory of Tree Genetics and Breeding, The Research Institute of Forestry, Chinese Academy of \\ Forestry, Beijing 100091, China \\ * Correspondence: ruizhao926@126.com (R.Z.); lschen@bjfu.edu.cn (S.C.); \\ Tel.: +86-10-6233-8129 (R.Z.); +86-10-6233-8129 (S.C.) \\ + These authors contributed equally to this work.
}

Received: 11 January 2019; Accepted: 11 February 2019; Published: 14 February 2019

check for updates

\begin{abstract}
Sodium chloride $(\mathrm{NaCl})$ induced expression of a jacalin-related mannose-binding lectin $(J R L)$ gene in leaves, roots, and callus cultures of Populus euphratica (salt-resistant poplar). To explore the mechanism of the PeJRL in salinity tolerance, the full length of PeJRL was cloned from P. euphratica and was transformed into Arabidopsis. PeJRL was localized to the cytoplasm in mesophyll cells. Overexpression of PeJRL in Arabidopsis significantly improved the salt tolerance of transgenic plants, in terms of seed germination, root growth, and electrolyte leakage during seedling establishment. Under $\mathrm{NaCl}$ stress, transgenic plants retained $\mathrm{K}^{+}$and limited the accumulation of $\mathrm{Na}^{+}$. PeJRL-transgenic lines increased $\mathrm{Na}^{+}$extrusion, which was associated with the upward regulation of SOS1, AHA1, and AHA2 genes encoding plasma membrane $\mathrm{Na}^{+} /$proton $\left(\mathrm{H}^{+}\right)$antiporter and $\mathrm{H}^{+}$-pumps. The activated $\mathrm{H}^{+}$-ATPases in PeJRL-overexpressed plants restricted the channel-mediated loss of $\mathrm{K}^{+}$that was activated by $\mathrm{NaCl}$-induced depolarization. Under salt stress, $\mathrm{PeJRL}$-transgenic Arabidopsis maintained reactive oxygen species (ROS) homeostasis by activating the antioxidant enzymes and reducing the production of $\mathrm{O}_{2}{ }^{-}$through downregulation of NADPH oxidases. Of note, the PeJRL-transgenic Arabidopsis repressed abscisic acid (ABA) biosynthesis, thus reducing the ABA-elicited ROS production and the oxidative damage during the period of salt stress. A schematic model was proposed to show the mediation of PeJRL on ABA response, and ionic and ROS homeostasis under $\mathrm{NaCl}$ stress.
\end{abstract}

Keywords: jacalin-related lectin; Populus euphratica; $\mathrm{NaCl}$; antioxidant enzyme; abscisic acid; $\mathrm{K}^{+} / \mathrm{Na}^{+}$ homeostasis; non-invasive micro-test technique

\section{Introduction}

Plants are frequently challenged by various environmental stressors, which inhibit plant growth and crop production. Among these unfavourable environmental factors, salinity presents a serious threat to plant growth and development [1-4]. Salt stress leads to water deficiency and ion toxicity, which cause oxidative damage in plants $[5,6]$. In addition, high salt alters the expression level of 
stress-related genes that are involved in ionic homeostasis and anti-oxidant defense [7]. Accumulating evidence reveals that higher plants have developed signalling networks for sensing and adapting to salinity stress $[8,9]$. Lectins are able to bind carbohydrates $[10,11]$ and play an important role in plant adaptation to adverse environments [12]. It has been shown that plant lectins inhibit infection of pathogen fungi and insects [13-15]. In wheat, jacalin-related lectin (JRL) genes such as TaJRL2.1, TaJRL53, TaJRL18.2, TaJRL27, TaJRL43, and TaJRL48 are induced in inflorescence after Fusarium graminearum inoculation, and TaJRL55 is induced by Hessian fly infection [16]. Allium sativum ASAL, a novel garlic lectin, is toxic towards hemipteran pests in $A S A L$-transgenic plants [14]. The snowdrop lectin GNA (Galanthus nivalis agglutinin) confers resistance to sap-sucking insects, e.g., brown planthopper (Nilaparvata lugens) [13]. Xiang et al. (2011) suggest that TaJRLL1 serves as a signalling component in the jasmonate (JA)- and salicylic acid (SA)-dependent defence pathways [15]. TaJRLL1-transformed Arabidopsis thaliana were shown to be resistance to Botrytis cinerea and Fusarium graminearum [15]. In addition to biotic stress, several lectin genes also exhibit different expressions under abiotic stress [16-18]. Digital expression analysis (DEA) has shown that 25 TaJRL genes were responsive to abiotic stress, such as water shortage, low temperature, aluminium, and salt stress [16]. A rice (Oryza sativa L.) lectin was isolated from salt-stressed plants and previously characterized by Zhang et al. (2000) [19]. Recently, OsJRL overexpression resulted in enhanced tolerance to $\mathrm{NaCl}$ in Escherichia coli and rice [18]. The OsJRL is also suggested to be involved in stress signal transduction and cell protection in rice [18]. However, the regulatory roles of Populus JRL family genes in salt tolerance are not yet fully understood in trees.

The phytohormone abscisic acid (ABA) is crucial for plant adapting to unfavourable environmental conditions [20-23]. High salinity and drought dramatically increase the ABA level, which in turn induces the expression of many genes involved in stress responses [24]. Abscisic acid has been shown to increase the synthesis of lectin in wheat cell cultures [25]. Furthermore, $O S J R L$ transcription is induced in response to ABA treatment in O. sativa subspecies japonica "Nipponbare" [18]. It is interesting to find that overexpression of OsJRL resulted in ABA sensitivity in rice [18]. It is suggested that OsJRL overexpressing in rice strengthened the salt stress signal; this would increase ABA sensitivity, thus leading to increased transcription of downstream salt-responsible genes [18]. At present, the sensitivity to ABA and the relevance to salt tolerance have scarcely been investigated in plants overexpressing $J R L$ from tree species.

Populus euphratica has been considered as a salt-resistant model species to address stress physiology in woody plants [8]. Populus euphratica retains a greater capacity to control reactive oxygen species (ROS) and $\mathrm{K}^{+} / \mathrm{Na}^{+}$homeostasis under saline conditions [5-8,26-32]. The signalling network of $P$. euphratica upon salt stress has been extensively investigated in previous studies [33-35]. In the present study, we observed that salt treatment increased PeJRL expression in P. euphratica leaves, roots, and callus cells. To determine whether PeJRL contributed to salt tolerance, PeJRL was cloned from P. euphratica and introduced into Arabidopsis, the model plant. We examined ion relations, ROS production, activity of antioxidant enzymes, and transcription of encoding genes, such as superoxide dismutase (SOD), catalase (CAT), and peroxidase (POD) under $\mathrm{NaCl}$ stress. The aim was to evaluate the contribution of PeJRL in ionic homeostasis control and anti-oxidative defence in transgenic plants. In addition, the sensitivity to ABA in Arabidopsis overexpressing PeJRL and the relevance to salt tolerance were investigated in the present study. Our data showed that PeJRL overexpression increased plants' ability to retain $\mathrm{K}^{+}$and $\mathrm{Na}^{+}$homeostasis during the observation period of $\mathrm{NaCl}$ treatment. Moreover, the PeJRL-overexpressing-plants maintained ROS homeostasis by activating the antioxidant enzymes and repressing ABA biosynthesis, thus reducing the ABA-elicited ROS production and the oxidative damage during the period of salt stress. 


\section{Results}

\subsection{Expression Profile of PeJRL upon Salt Exposure in Populus euphratica}

To determine whether PeJRL was responsive to salt stress in P. euphratica, real-time quantitative PCR (RT-qPCR) was used to examine PeJRL transcript levels in callus cells, leaves, and roots. Exposure to $\mathrm{NaCl}(125-200 \mathrm{mM})$ significantly increased PeJRL transcript levels relative to the reference gene in P. euphratica, although the pattern varied between callus, leaves, and roots (Figure 1). In callus cells, the transcripts of PeJRL rapidly increased up to 3.59 fold after $12 \mathrm{~h}$ of salt treatment, then reached 7.72 fold at $24 \mathrm{~h}$ (Figure 1A). In P. euphratica leaves, PeJRL transcript levels gradually increased upon salt exposure and reached the maximum after 6-12 h of salt treatment (Figure 1B). The PeJRL transcript abundance was maintained at relatively high levels (2-5 fold) in the following time of salinity (24-72 h; Figure 1B). In P. euphratica roots, PeJRL transcript levels increased rapidly at $3 \mathrm{~h}$ after salt treatment and reached peak levels until $6 \mathrm{~h}$, and then returned to the pre-treatment level in the following hours (Figure 1C). The drop of expression showing at leaves $(24 \mathrm{~h})$ and roots $(12 \mathrm{~h})$ implied the recovery of whole-plant water status after salt shock $[29,36]$. The following increase of PeJRL transcript in leaves at 48-72 h was presumably the result of plant response to build-up of salt ions that translocated from roots to shoots. Collectively, these results demonstrated that $P e J R L$ was $\mathrm{NaCl}$-inductive in this salt-resistant poplar.

\subsection{PeJRL Protein Sequence and Phylogenetic Analysis}

Sequence and phylogenetic analyses were carried out to determine whether PeJRL belongs to jacalin-related mannose-binding lectins. The 1338-bp full-length cDNA of PeJRL was cloned from $P$. euphratica leaves. It encoded a putative protein of 445 amino acids (Figure 2A). The protein has a predicted molecular weight of $47.18 \mathrm{kDa}$ with an iso-electric point (pI) 5.94 (Figure 2A). The PeJRL amino acid sequence displays higher similarity to P. trichocarpa JRL (PtJRL) than that of other higher-order plants. The PeJRL protein contains a conserved $C$ terminal sequence, and three typical jacalin domains which are sugar-binding protein domains mostly found in higher plants (Figure 2A). Figure 2B shows the phylogenetic relationship between PeJRL and JRLs from other plant species. The constructed phylogenetic dendrogram shows the evolutionary conservation of PeJRL to other jacalin-related mannose-binding lectins (Figure 2B).

\subsection{Subcellular Localization of PeJRL}

Jacalin-related mannose-binding lectin has been shown to be a nucleocytoplasmic lectin in plants [18]. To visualize PeJRL localization within the cell, green fluorescent protein (GFP) was fused to the full-length PeJRL cDNA and transiently expressed in Arabidopsis protoplasts. Confocal laser scanning microscopy showed that PeJRL localized to the cytoplasm in the mesophyll cells (Figure 3A). However, the protoplasts transformed with GFP alone showed GFP fluorescence throughout the cytoplasm and nucleus (Figure 3B).

\subsection{Overexpression of PeJRL in Arabidopsis}

To elucidate the function of PeJRL in salt tolerance, the ORF of PeJRL was transformed into wildtype (WT) Arabidopsis under the control of CaMV $35 S$ promoter. Six independent transgenic lines, i.e., OE6, 7, 12, 18, 21, and 23 were obtained. Semi-quantitative reverse transcription PCR (RT-PCR) and RT-qPCR results showed that OE7 and OE23 had higher transcript levels of PeJRL than the other lines (Figure 4A,B). Therefore, these two lines were selected for subsequent phenotype tests.

\subsection{PeJRL Overexpression in Arabidopsis Enhanced Salt Tolerance}

To determine whether PeJRL affected salt tolerance during seedling establishment, seeds of wild-type (WT), vector control (VC), and transgenic plants were germinated on 1/2 Murashige-Skoog (MS) medium supplemented with increasing $\mathrm{NaCl}$ (75-125 mM for $10 \mathrm{~d}$, Figure 5A). The two transgenic 
lines performed much better than WT Arabidopsis and VC at $125 \mathrm{mM} \mathrm{NaCl}$, in terms of leaf opening and greening (Figure 5A). Root length was inhibited upon $\mathrm{NaCl}$ exposure, but the growth was less suppressed in transgenic lines at the tested concentrations (75 or $125 \mathrm{mM}$ ), as compared to WT and VC plants (Figure 5B,C).
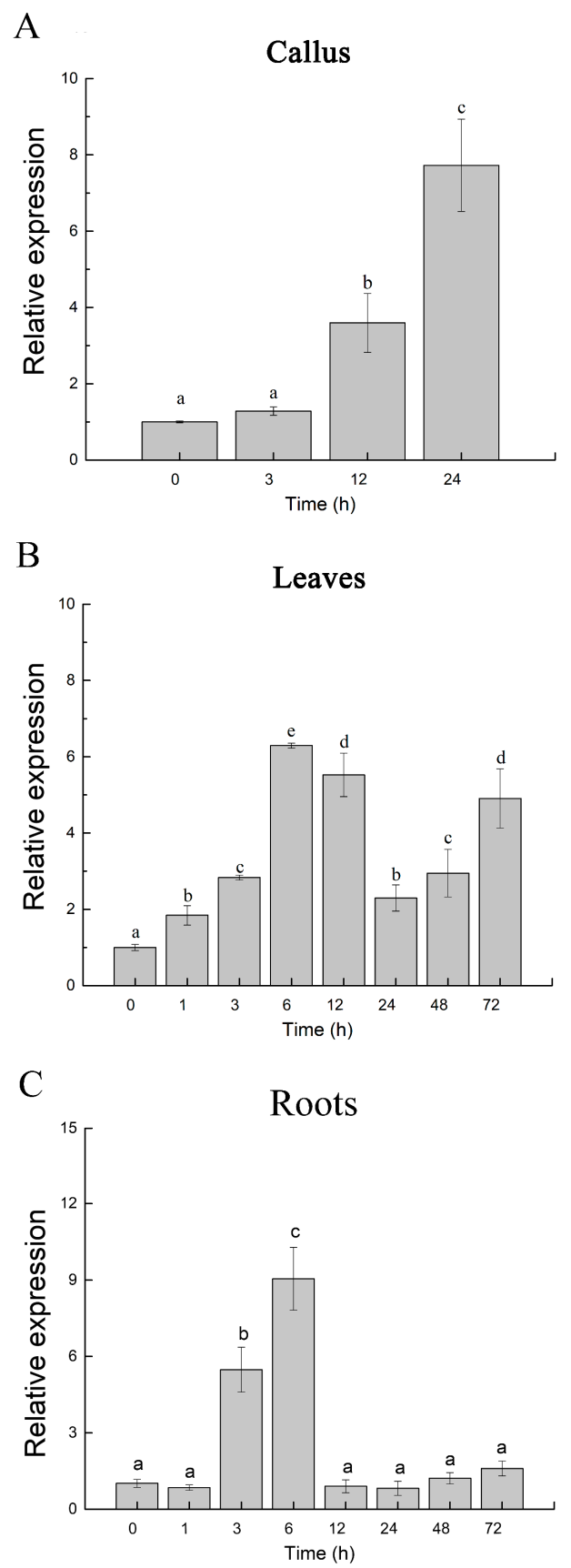

Figure 1. Expression level of jacalin-related mannose-binding lectin PeJRL gene in Populus euphratica callus cultures, leaves, and roots under $\mathrm{NaCl}$ treatment. (A) Callus cultures. PeJRL expression was measured using RT-qPCR during the period of salt treatment (125 mM NaCl, $24 \mathrm{~h}$ ). (B) Leaves. (C) Roots. PeJRL expression was examined with RT-qPCR in young leaves and roots during $\mathrm{NaCl}$ stress $(200 \mathrm{mM} \mathrm{NaCl}, 72 \mathrm{~h})$. Expression levels of PeJRL in this experiment were calculated relative to the $P$. euphratica housekeeping gene, PeACT7, an internal reference. Primers designed to target PeJRL and PeACT7 genes are shown in Supplementary Materials Table S1. Each column corresponds to the mean of three independent replicates, and bars represent the standard error of the mean. Columns labelled with different letters (a-e) denote significant differences, at $p<0.05$. 
A

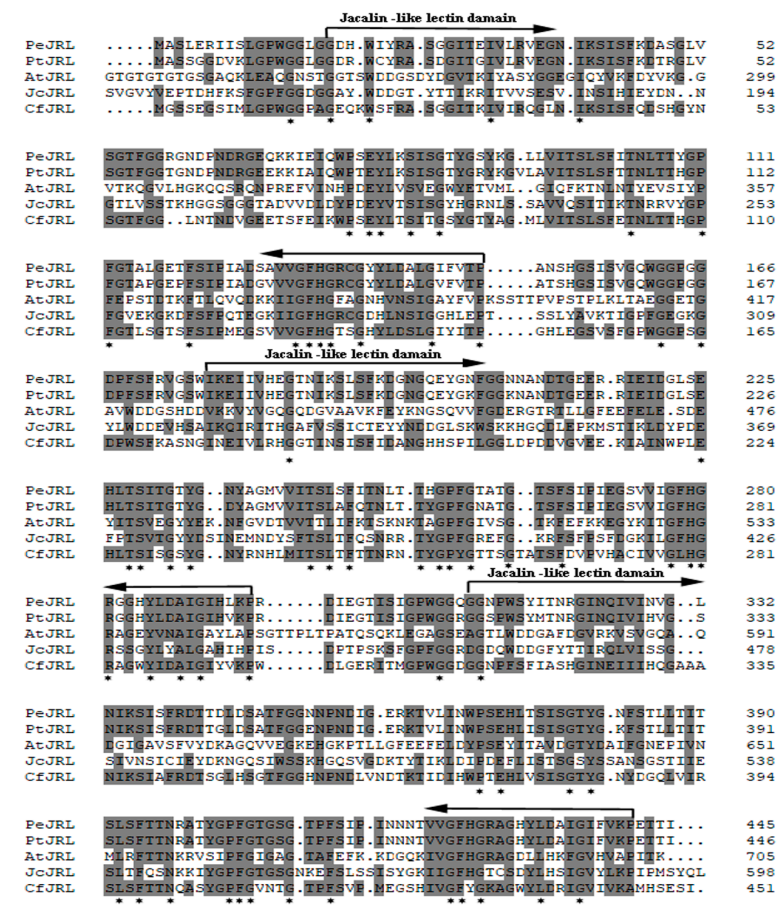

B

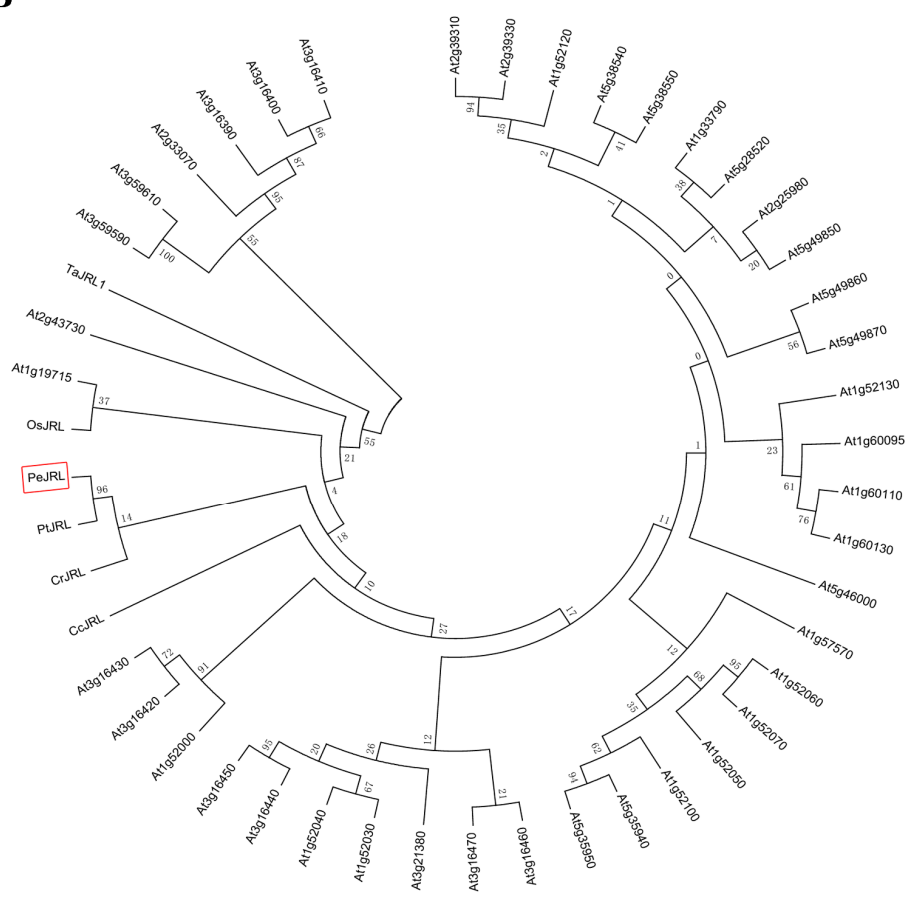

Figure 2. Comparative analysis of PeJRL proteins in different plant species. (A) Multiple sequence alignment of PeJRL with JRLs from other species. The JRL sequences are deduced from Populus trichocarpa (PtJRL, XP_024444915.1), Arabidopsis thaliana (AtJRL, AT3G16460), Jatropha curcas (JcJRL, XP_020533220.1), and Cephalotus follicularis (CfJRL, GAV61504.1). Grey shading and asterisks indicate conserved and invariant amino acid residues, respectively. Three jacalin-like lectin domains are shown with arrows. (B) Phylogenetic relationships between PeJRL and other $J R L$ family members from different species. The phylogenetic tree was constructed with the neighbour-joining method using MEGA 5.2. Bootstrap values of 1000 replicates. At, Arabidopsis thaliana; Cc, Castanea crenata; Cr, Cycas revolute; Os, Oryza sativa; Pe, Populus euphratica; Pt, Populus trichocarpa; Ta, Triticum aestivum. 
A
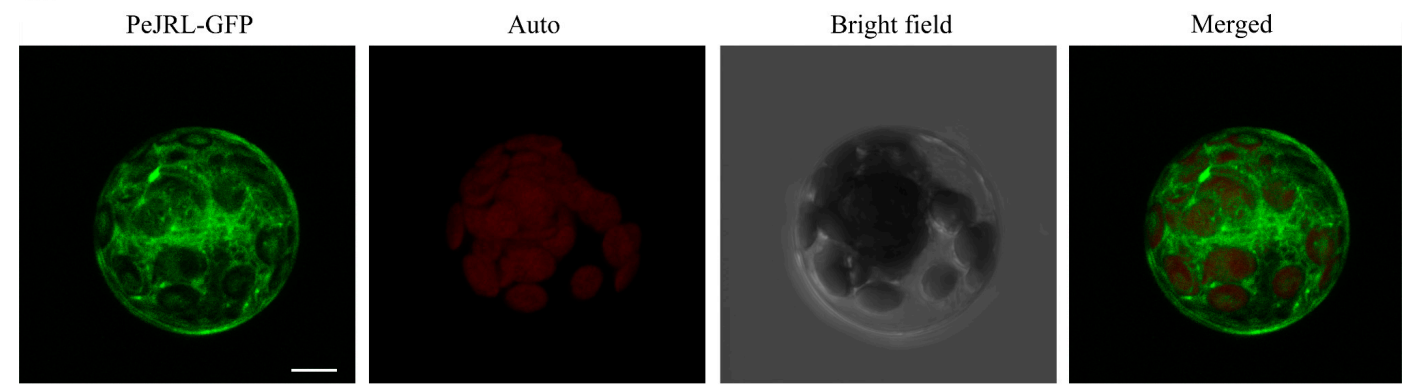

B
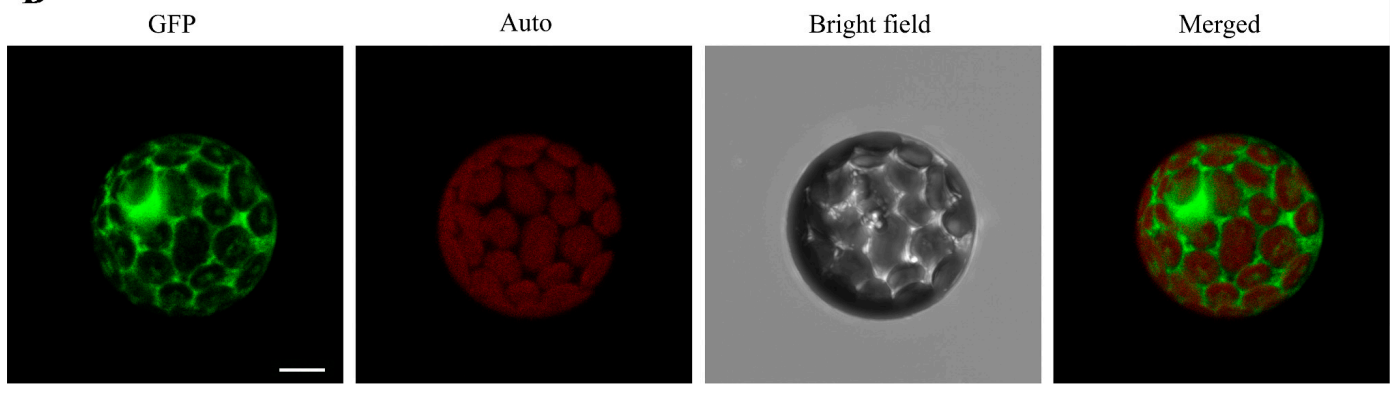

Figure 3. Subcellular localization of PeJRL by transient transformation in Arabidopsis mesophyll protoplasts. (A) Representative images of PeJRL-green fluorescent protein (GFP) in Arabidopsis protoplasts. (B) Control images for GFP vector. Green fluorescence was evenly detected in the cytosolic and nuclear spaces. Experiments were repeated four times with the same results. Scale bars $=5 \mu \mathrm{m}$.

$\mathbf{A}$

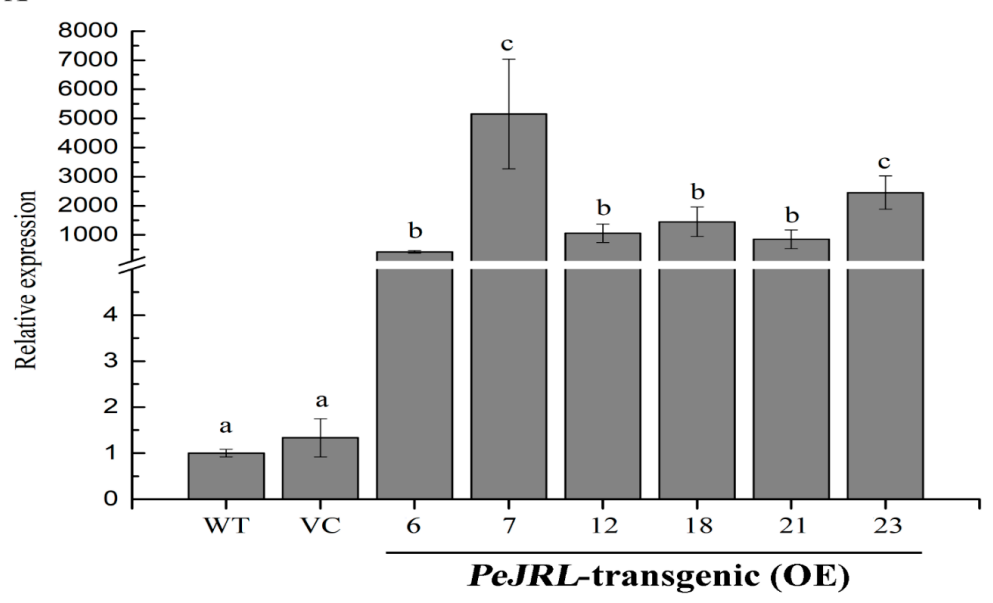

B

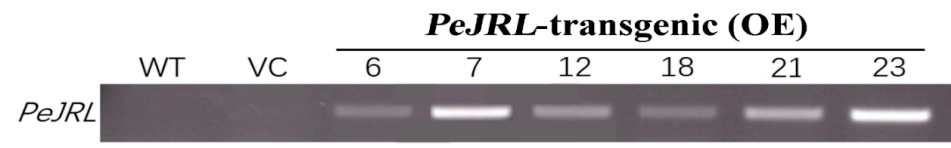

AtACTIN2

Figure 4. Overexpression of PeJRL in Arabidopsis. (A) RT-qPCR assays of PeJRL overexpression (OE) after transformation. Arabidopsis thaliana actin 2 (AtACTIN2) served as the internal control. Forward and reverse primers are shown in Supplementary Materials Table S1. Each column corresponds to the mean of three individual plants, and bars represent the standard error of the mean. Columns labelled with different letters $(\mathrm{a}-\mathrm{c})$ indicate significant differences $(p<0.05)$ between wild-type $(\mathrm{WT})$, vector control (VC), and transgenic lines. (B) Semi-quantitative reverse-transcription PCR (RT-PCR) analysis of PeJRL in WT, VC, and transgenic lines (\#6, \#7, \#12, \#18, \#21, and \#23). 
A
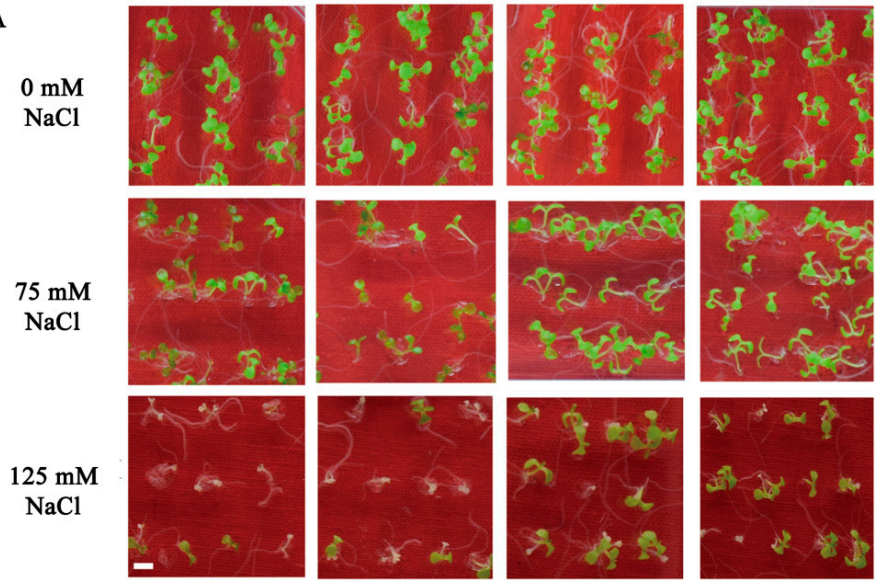

VC

PeJRL-OE7

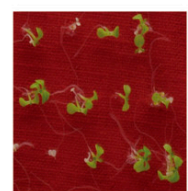

WT

PeJRL-OE23

B

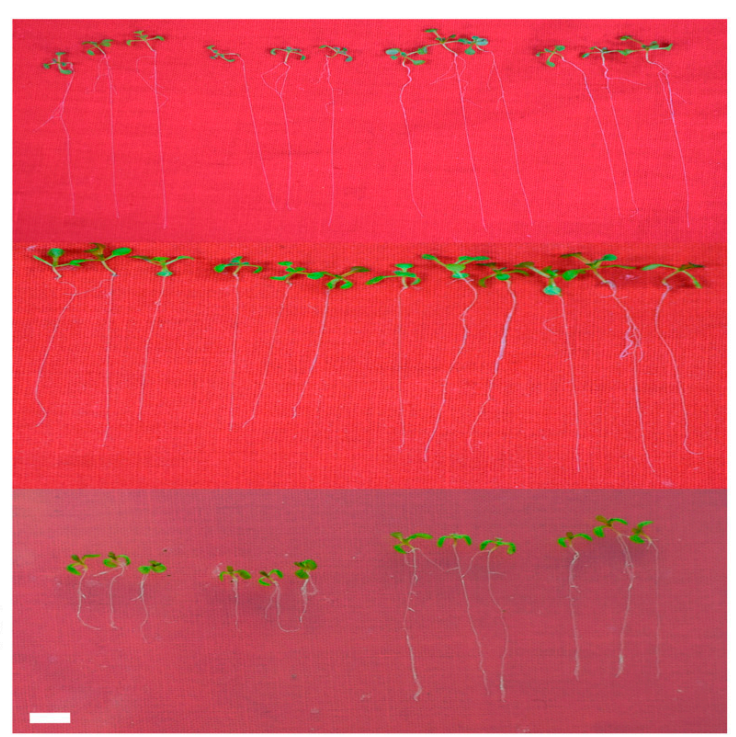

WT

vC

PeJRL-OE7 PeJRL-OE23

C

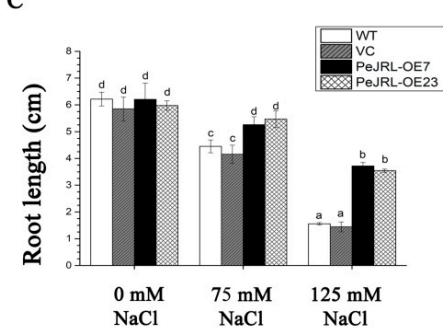

D

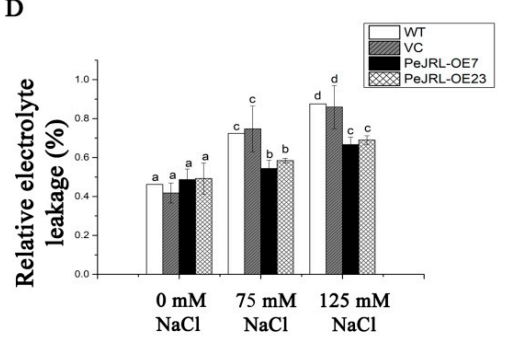

Figure 5. Salt tolerance tests in WT, VC, and PeJRL-transgenic Arabidopsis lines (OE7 and OE23). Seeds of WT, VC, and transgenic lines were allowed to germinate on 1/2 Murashige-Skoog (MS) medium supplemented with 0,75 or $125 \mathrm{mM} \mathrm{NaCl}$. Representative images show plant performance during seedling establishment $(\mathbf{A})$ and root length $(\mathbf{B}, \mathbf{C})$ after 10 days of $\mathrm{NaCl}$ stress $(0,75$ or $125 \mathrm{mM})$. Each column corresponds to the mean of three independent experiments (70 seeds for each test). (D) Relative electrolyte leakage. Electrolyte leakage was measured after 10 days of $\mathrm{NaCl}$ stress $(0,75$ or $125 \mathrm{mM})$. Each column corresponds to the mean of three replicated experiments ( 20 seeds for each test) and bars represent the standard error of the mean. In $\mathbf{C}$ and $\mathbf{D}$, columns labelled with different letters (a-d) denote significant differences at $p<0.05$. Scale bar $=1 \mathrm{~cm}(\mathbf{A}, \mathbf{B})$. 
Electrolyte leakage (EL) is an important indicator reflecting the membrane permeability and lipid peroxidation under stress conditions [5]. Electrolyte leakage was examined to determine whether the salt treatment disrupted the plasma membrane. Electrolyte leakage detected in all lines increased with the increasing $\mathrm{NaCl}$ concentrations (Figure 5D). There were significant differences in EL among WT, VC, and transgenic lines after exposure to 75 or $125 \mathrm{mM} \mathrm{NaCl}$. The PeJRL-overexpressed lines exhibited significantly lower EL than WT and VC under salt stress (Figure 5D), indicating that the membrane integrity of transgenic plants was less disrupted by lipid peroxidation.

\section{6. $\mathrm{Na}^{+}$Concentrations in Roots}

It has been previously shown that salt-tolerant plants could control $\mathrm{Na}^{+}$uptake and avoid an excessive accumulation $[20,26,28]$. To determine whether PeJRL contributed to controlling the $\mathrm{Na}^{+}$ accumulation, $\mathrm{Na}^{+}$concentrations within root cells were detected with a $\mathrm{Na}^{+}$specific probe, CoroNa ${ }^{\mathrm{TM}}$ Green [35]. The concentrations of $\mathrm{Na}^{+}$significantly increased after $12 \mathrm{~h}$ of salt treatment (Figure 6). The fluorescence intensity in WT Arabidopsis and VC was greater than that observed in OE7 and OE23 (Figure 6B). The specific fluorescence intensity was almost non-detectable under control conditions (Figure 6A), indicating that the $\mathrm{Na}^{+}$concentration was very low in the roots of all tested genotypes.

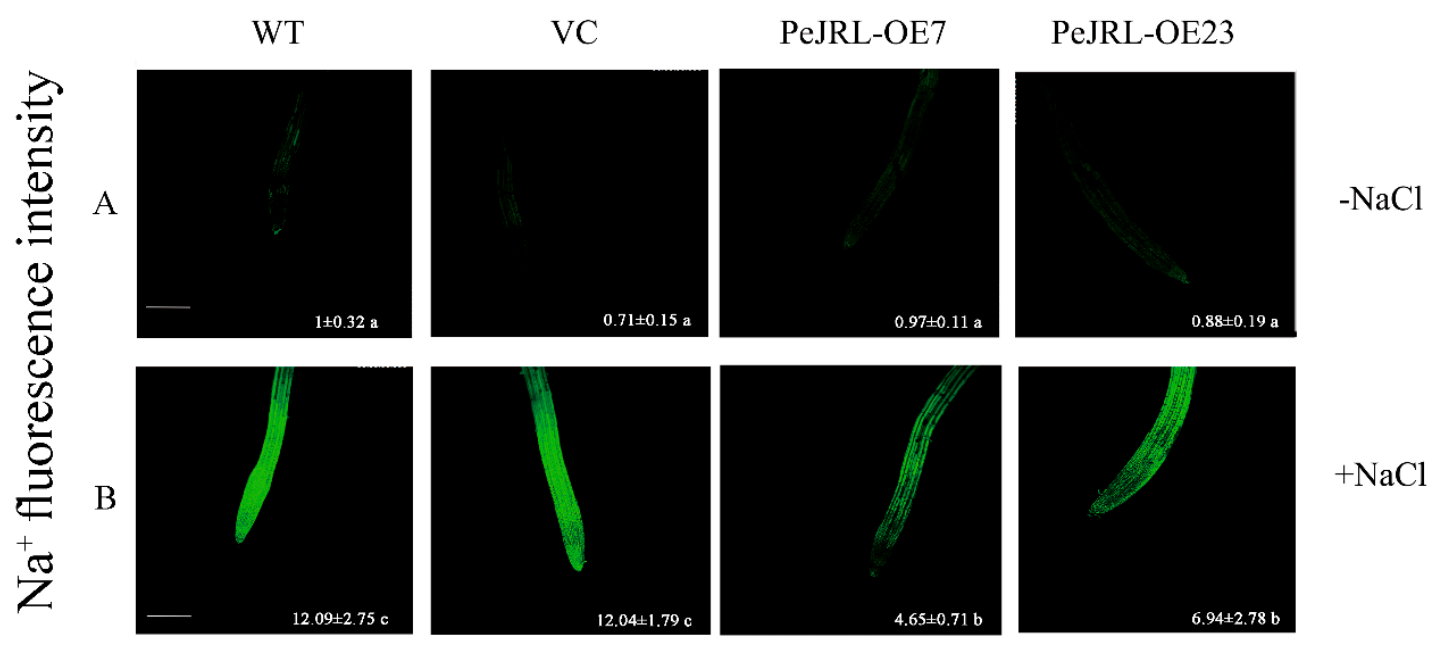

Figure 6. $\mathrm{Na}^{+}$fluorescence intensity in root cells of wild-type (WT) Arabidopsis, vector control (VC), and PeJRL-transgenic lines (OE7 and OE23) under $\mathrm{NaCl}$ stress. Seven-day-old seedlings were exposed to $1 / 2 \mathrm{MS}$ liquid medium supplemented with or without $125 \mathrm{mM} \mathrm{NaCl}$ for $12 \mathrm{~h}$, then incubated with CoroNa-Green AM to detect $\mathrm{Na}^{+}$concentrations. Green fluorescence in root cells was measured at the apical region of roots under a Leica confocal microscope. Representative confocal images show $\mathrm{Na}^{+}$fluorescence intensity in control $(-\mathrm{NaCl})(\mathbf{A})$ and salt-stressed roots $(+\mathrm{NaCl})(\mathbf{B})$. Values $( \pm \mathrm{SE})$ show the mean fluorescence intensity of CoroNa-Green AM. Each value corresponds to the mean of 6-9 independent plants. Values labelled with different letters $(\mathrm{a}-\mathrm{c})$ donate significant differences at $p<0.05$. Scale bar $=250 \mu \mathrm{m}$.

\section{7. $\mathrm{Na}^{+}, \mathrm{K}^{+}$, and $\mathrm{H}^{+}$Fluxes in Root Tips and Transcription of $\mathrm{K}^{+} / \mathrm{Na}^{+}$Homeostasis Genes}

The ability to retain $\mathrm{K}^{+} / \mathrm{Na}^{+}$homeostasis is critical for plant adaptation to salt stress [31-34]. To determine whether PeJRL contributed to maintaining the ionic homeostasis, the root ionic fluxes were examined by non-invasive micro-test technique (NMT) in all test lines. Non-invasive micro-test technique recording of roots showed that $\mathrm{NaCl}$ caused an increased efflux of $\mathrm{Na}^{+}$in all tested lines (Figure 7A). It is worth noting that transgenic plants exhibited three-fold higher $\mathrm{Na}^{+}$efflux than WT and $\mathrm{VC}$ after $12 \mathrm{~h}$ of $\mathrm{NaCl}$ stress (Figure 7A). In all tested roots, the influx of $\mathrm{H}^{+}$was shifted to efflux by $\mathrm{NaCl}$ treatment (Figure 7B). However, the $\mathrm{H}^{+}$effluxes in transgenic lines were notably higher than in WT Arabidopsis and VC (2-fold, Figure 7B). $\mathrm{NaCl}$ exposure increased the efflux of $\mathrm{K}^{+}$in all tested lines, while transgenic plants exhibited lower $\mathrm{K}^{+}$loss than in WT Arabidopsis and VC (Figure 7C). 
The $\mathrm{Na}^{+}$extrusion and $\mathrm{K}^{+}$maintenance depends on the activity of $\mathrm{Na}^{+} / \mathrm{H}^{+}$antiporters and $\mathrm{H}^{+}$-pumps in the plasma membrane (PM) $[8,33]$. The transcript abundance of $\mathrm{K}^{+} / \mathrm{Na}^{+}$homeostasisrelated genes encoding plasma membrane $\mathrm{H}^{+}$-ATPases (AtAHA1 and AtAHA2), $\mathrm{Na}^{+} / \mathrm{H}^{+}$antiporter (AtSOS1), and high-affinity $\mathrm{K}^{+}$transporter (AtHKT1) were compared under $\mathrm{NaCl}$ stress. The expression of AtAHA1, AtAHA2, AtSOS1, and AtHKT1 were significantly higher in transgenic plants than in the WT and VC (Figure 7D).

A

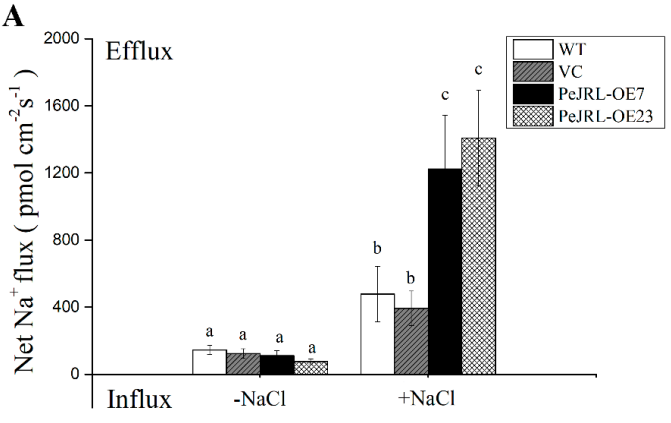

B

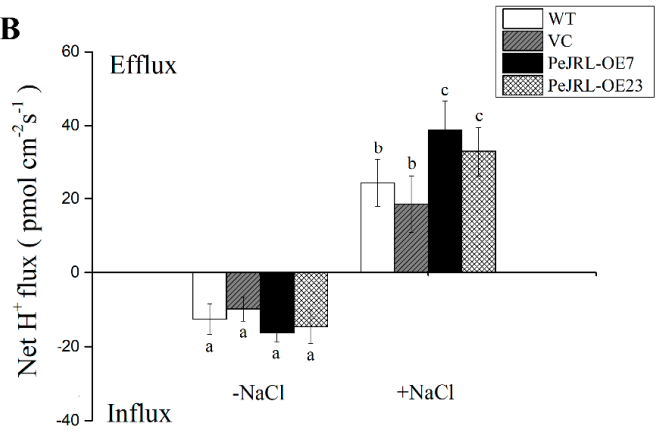

C

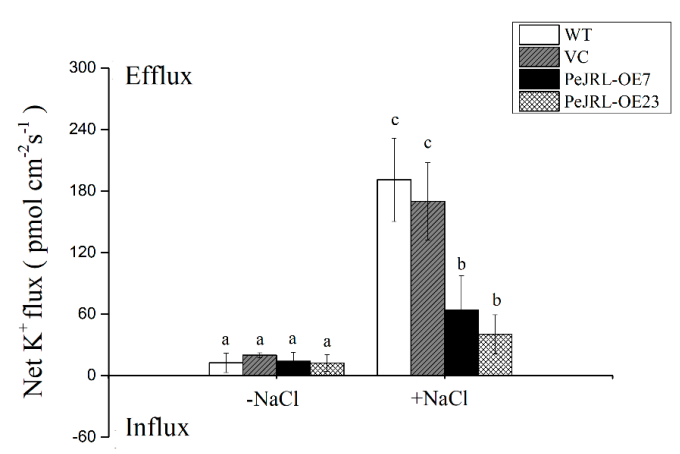

D

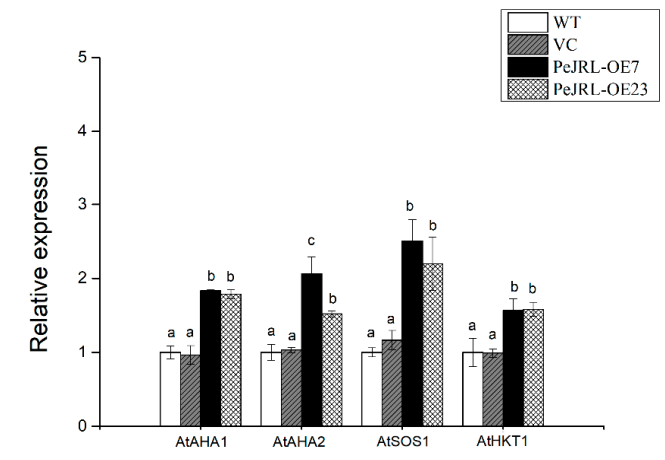

Figure 7. Effects of $\mathrm{NaCl}$ on $\mathrm{Na}^{+}, \mathrm{K}^{+}$, and $\mathrm{H}^{+}$fluxes and transcription of $\mathrm{K}^{+} / \mathrm{Na}^{+}$homeostasis genes in roots of wild-type (WT) Arabidopsis, vector control (VC), and PeJRL-transgenic lines (OE7 and OE23). Seven-day-old seedlings were treated without or with $\mathrm{NaCl}(125 \mathrm{mM})$ for $12 \mathrm{~h}$. Steady-state flux profiles of $\mathrm{Na}^{+}(\mathbf{A}), \mathrm{H}^{+}(\mathbf{B})$, and $\mathrm{K}^{+}(\mathbf{C})$ in roots of WT Arabidopsis, VC, and PeJRL-transgenic lines (PeJRL-OE7 and PeJRL-OE23) were measured at the apical zone (ca $200 \mu \mathrm{m}$ from the root apex) for 10 min. Mean fluxes of no-salt control $(-\mathrm{NaCl})$ and salt-stressed roots $(+\mathrm{NaCl})$ are shown. (D) Relative expression levels of AHA1, AHA2, SOS1, and HKT1 in WT Arabidopsis, VC, and PeJRL-transgenic lines (OE7 and OE23) under $\mathrm{NaCl}$ treatment. Transcription of AHA1, AHA2, SOS1, and HKT1 was detected with RT-qPCR. The Arabidopsis AtACTIN2 was used as the internal control. Primers designed to target AtAHA1, AtAHA2, AtSOS1, and AtHKT1, and AtACTIN2 genes are shown in Supplementary Materials Table S1. Each column corresponds to the mean of three (D) to seven (A-C) independent plants, and bars represent the standard error of the mean. For each tested gene, columns labelled with different letters $(\mathrm{a}-\mathrm{c})$ denote significant difference between $\mathrm{WT}, \mathrm{VC}$, and transgenic lines at $p<0.05$.

\subsection{Anti-Oxidative Enzyme Activity and Transcript Levels of Encoding Genes}

Salt stress-elicited ROS causes oxidative damage to plant cells [5,6]. It is critically important to enhance ROS-scavenging capacity by increasing the activity of anti-oxidative enzymes under saline conditions $[5,6]$. To determine whether PeJRL overexpression could affect activities of anti-oxidative enzymes, SOD, POD, and CAT activities were measured in all tested lines under salt treatment. Transgenic lines retained significantly higher activity of these antioxidant enzymes than WT Arabidopsis and VC (Figure 8A,C,E). The gene expression of $S O D, P O D$, and $C A T$ displayed a high similarity to the pattern of their activity profiles under $\mathrm{NaCl}$ stress. Transgenic plants retained higher transcription levels of $A t S O D, A t C A T$, and $A t P O D$ relative to the WT Arabidopsis and VC (Figure 8B,D,F). 

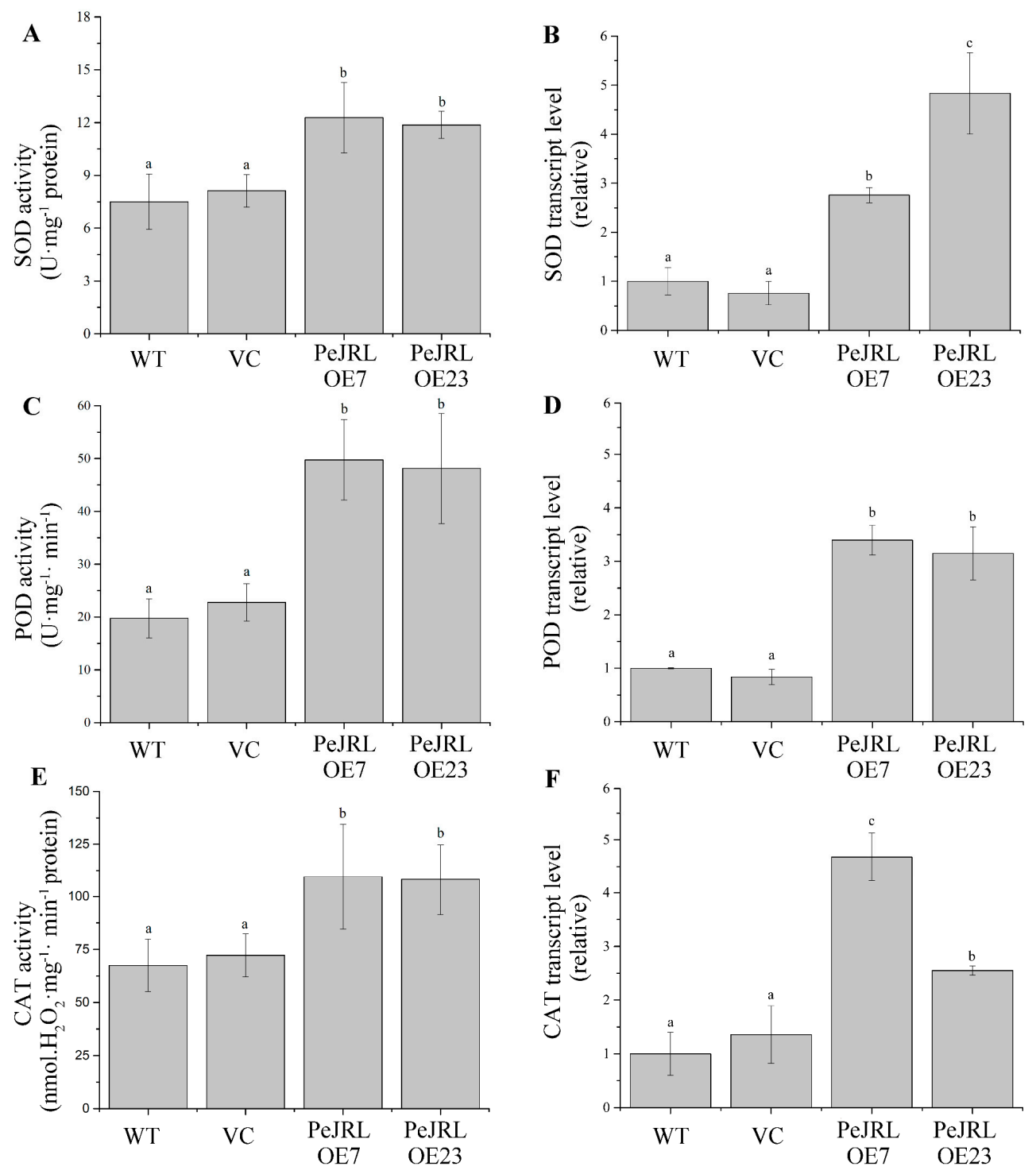

Figure 8. Effect of $\mathrm{NaCl}(75 \mathrm{mM}, 10 \mathrm{~d})$ on total activities of superoxide dismutase (SOD), catalase (CAT), peroxidase (POD), and transcription levels of encoding genes in wild-type (WT) Arabidopsis, vector control (VC), and PeJRL-transgenic lines (OE7 and OE23). (A,C,E) Total activities. (B,D,F) Transcription levels. Transcription of AtSOD, AtPOD, and AtCAT was detected with RT-qPCR. The Arabidopsis AtACTIN2 was used as the internal control. Primers designed to target AtSOD, AtPOD, AtCAT, and AtACTIN2 genes are shown in Supplementary Materials Table S1. Each column corresponds to the mean of three replicated experiments, and bars represent the standard error of the mean. Columns labelled with different letters $(\mathrm{a}-\mathrm{c})$ denote significant difference at $p<0.05$.

\section{9. $\mathrm{H}_{2} \mathrm{O}_{2}$ Levels in Root Cells and Transcription of AtRBOHD and AtRBOHF}

The concentration of $\mathrm{H}_{2} \mathrm{O}_{2}$ could reflect the capacity of ROS-scavenging capacity in salt-stressed plants [5,6]. Hydrogen peroxide production was examined to determine whether PeJRL-transgenic plants could control ROS homeostasis under $\mathrm{NaCl}$ stress. The salt treatment significantly increased $\mathrm{H}_{2} \mathrm{O}_{2}$ levels in WT, VC, and PeJRL-transgenic roots (Figure 9A). However, salinized transgenic plants retained obviously lower $\mathrm{H}_{2} \mathrm{O}_{2}$ levels than that in WT Arabidopsis and VC (Figure 9A). In accordance, transgenic lines remained lower transcription of $A t R B O H D$ and AtRBOHF genes, encoding Arabidopsis reduced nicotinamide adenine dinucleotide phosphate (NADPH) oxidases, under salt treatment (Figure 9B,C). The transcripts of AtRBOHD were similar in no-salt control plants of all tested lines, although PeJRL-transgenic lines exhibited lower AtRBOHF transcript than WT and VC (Figure 9B,C). 


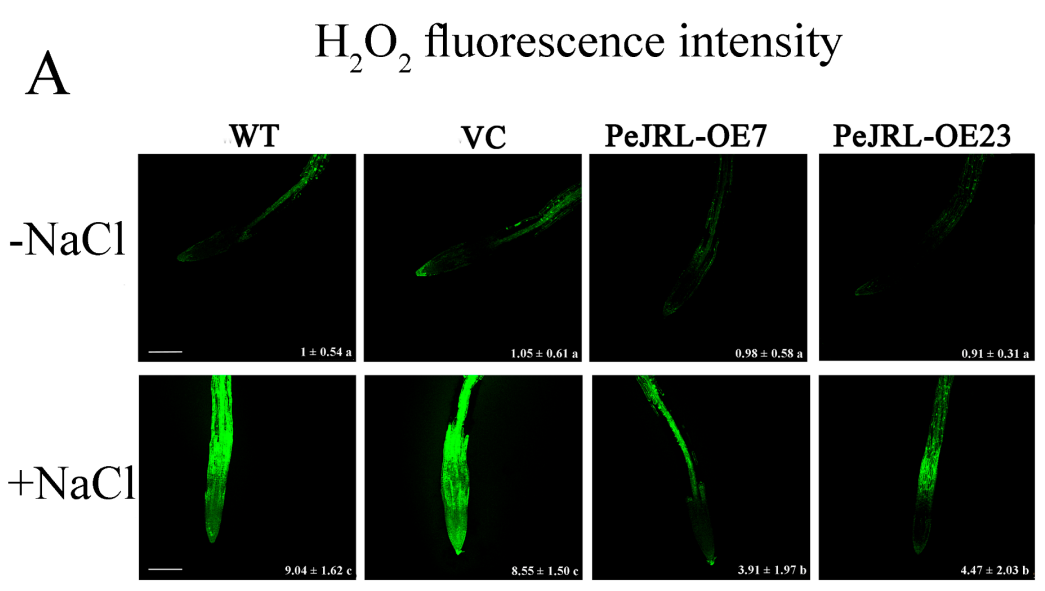

B

AtRBOHD

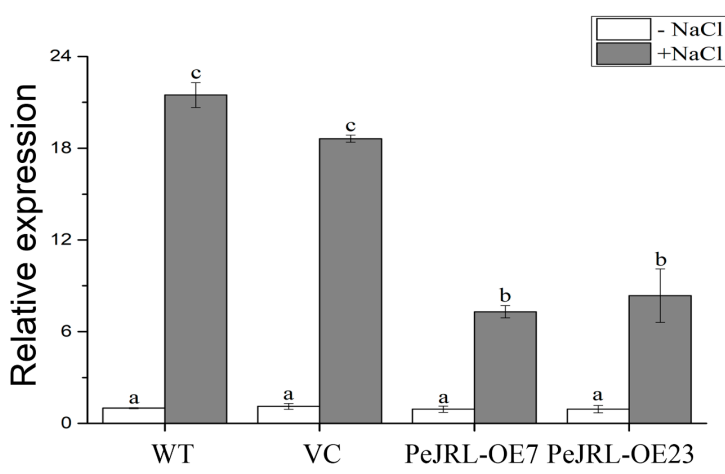

C

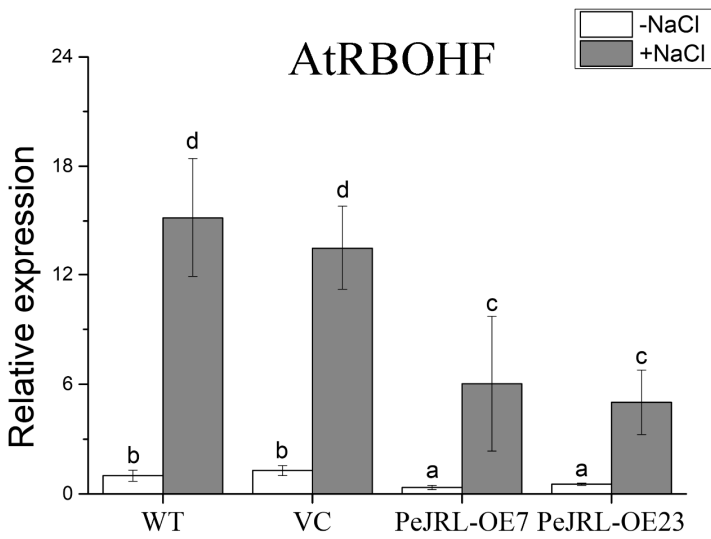

Figure 9. Effect of $\mathrm{NaCl}$ on root $\mathrm{H}_{2} \mathrm{O}_{2}$ production, $A t R B O H D$ and $A t R B O H F$ expression in wild-type (WT) Arabidopsis, vector control (VC), and PeJRL-transgenic lines (OE7 and OE23). (A) $\mathrm{H}_{2} \mathrm{O}_{2}$ fluorescence intensity. Seven-day-old seedlings were treated without or with $\mathrm{NaCl}(125 \mathrm{mM})$ for $12 \mathrm{~h}$. Roots were then incubated with $2^{\prime}, 7^{\prime}$-dichlorodihydro-fluorescein diacetate $\left(\mathrm{H}_{2} \mathrm{DCF}-\mathrm{DA}, 10 \mu \mathrm{M}\right)$ for $5 \mathrm{~min}$. Green fluorescence within cells was detected at the apical region of roots under a Leica confocal microscope. Representative confocal images of $\mathrm{H}_{2} \mathrm{O}_{2}$ production in control $(-\mathrm{NaCl})$ and salt-stressed roots $(+\mathrm{NaCl})$ are shown. Values $( \pm \mathrm{SE})$ show the mean fluorescence intensity of $\mathrm{H}_{2} \mathrm{DCF}-\mathrm{DA}$. Each value corresponds to the mean of three replicated experiments and values labelled with different letters $(\mathrm{a}-\mathrm{c})$ indicate significant differences at $p<0.05$. (B) AtRBOHD and (C) AtRBOHF expression. Five-day-old seedlings were transferred to MS medium containing 0 or $75 \mathrm{mM} \mathrm{NaCl}$ for 10 days. AtRBOHD and AtRBOHF transcription were detected with RT-qPCR. The Arabidopsis AtACTIN2 was used as the internal control. Primers designed to target AtRBOHD, AtRBOHF, and AtACTIN2 genes are shown in Supplementary Materials Table S1. Each column corresponds to the mean of seven independent plants, and bars represent the standard error of the mean. Columns labelled with different letters $(\mathrm{a}-\mathrm{d})$ denote significant difference at $p<0.05$. Scale bar $=250 \mu \mathrm{m}(\mathbf{A})$. 


\subsection{PeJRL Overexpression Increased ABA Sensitivity in the Presence and Absence of Salt}

It is suggested that a rice JRL enhances salt stress signalling by increasing the sensitivity to ABA [18]. To determine whether PeJRL is involved in the ABA signalling pathway, the sensitivity to ABA was examined in PeJRL-transgenic plants. In the absence of $\mathrm{NaCl}$, overexpression of PeJRL increased the sensitivity to ABA in Arabidopsis. Exogenous ABA, at a dose of 0.6 or $5 \mu \mathrm{M}$, caused a more pronounced reduction of plant growth and root length in PeJRL-transgenic lines, compared with the WT Arabidopsis and VC (Figure 10A-C). Abscisic acid at the tested doses $(0.6$ or $5 \mu \mathrm{M})$ increased EL in all tested lines, but a more pronounced enhancement was observed in transgenic lines (Figure 10D).

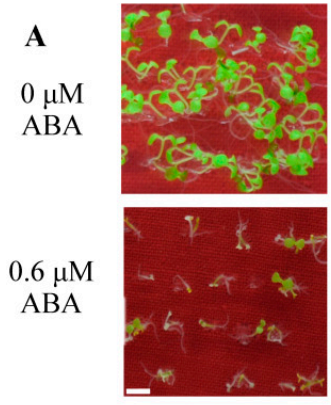

WT
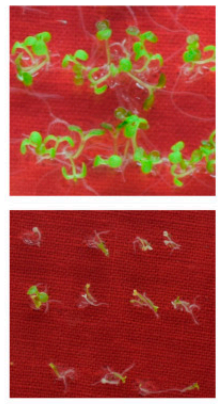

VC
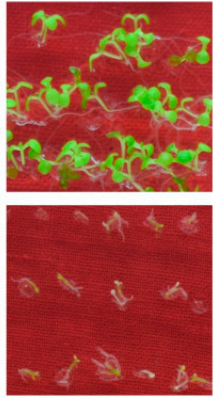

PeJRL

OE7
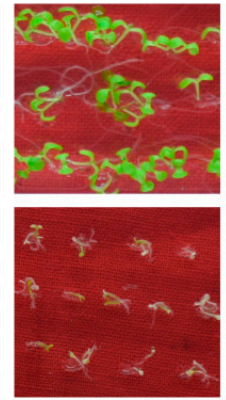

PeJRL

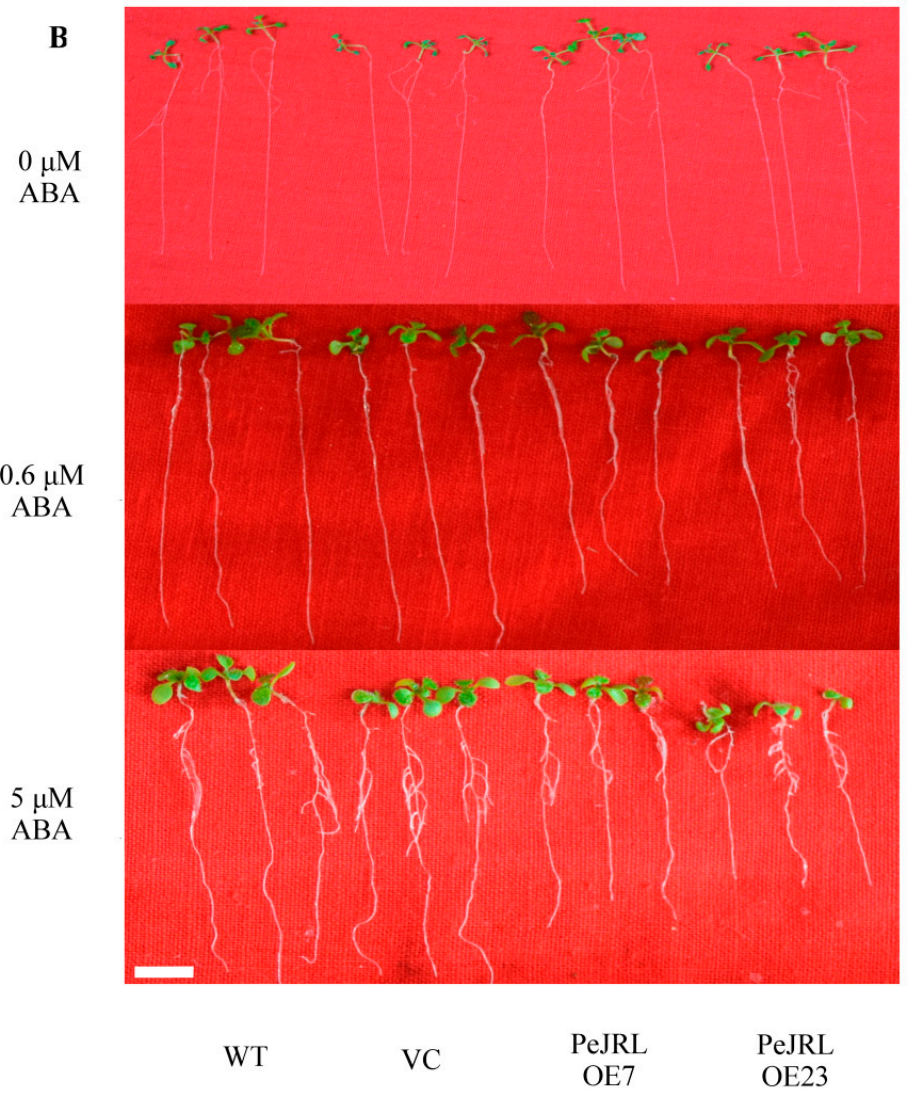

Figure 10. Cont. 

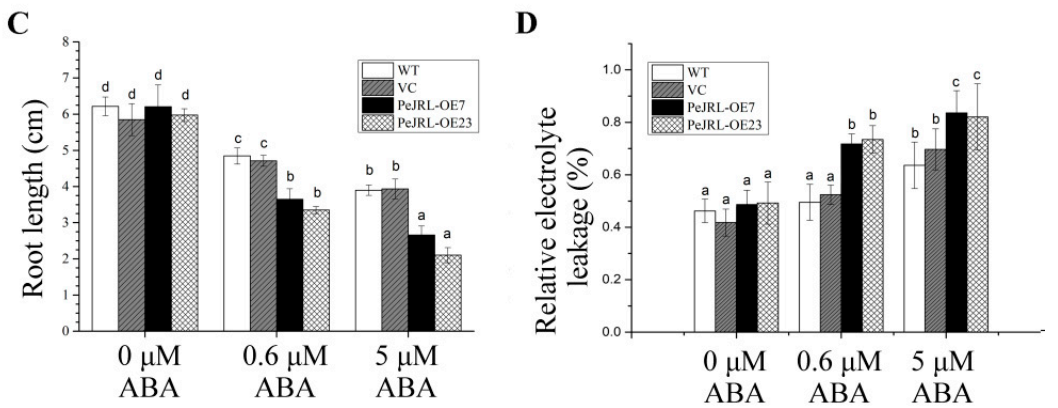

Figure 10. Abscisic acid (ABA) tests in wild-type (WT), vector control (VC), and PeJRL-transgenic Arabidopsis lines (OE7 and OE23). Seeds of WT, VC, and transgenic lines were allowed to germinate on MS medium supplemented with $0,0.6$ or $5 \mu \mathrm{M}$ ABA. Representative images show plant performance during seedling establishment $(\mathbf{A})$ and root length $(\mathbf{B}, \mathbf{C})$ after 10 days of ABA treatment $(0,0.6$ or $5 \mu \mathrm{M})$. Each column in (C) corresponds to the mean of three independent experiments (70 seeds for each test), and bars represent the standard error of the mean. (D) Relative electrolyte leakage. Electrolyte leakage was measured after 10 days of ABA treatment $(0,0.6$ or $5 \mu \mathrm{M})$. Each column corresponds to the mean of three replicated experiments (20 seeds for each test) and bars represent the standard error of the mean. In $\mathbf{C}$ and $\mathbf{D}$, columns labelled with different letters $(\mathrm{a}-\mathrm{d})$ denote significant differences at $p<0.05$. Scale bar $=1 \mathrm{~cm}(\mathbf{A}, \mathbf{B})$.

In the presence of $\mathrm{NaCl}, \mathrm{ABA}$ increased $\mathrm{H}_{2} \mathrm{O}_{2}$ content in all tested lines (Figure 11A). In comparison, the ABA-elicited $\mathrm{H}_{2} \mathrm{O}_{2}$ increase was more pronounced in transgenic lines, because these plants retained a lower level of $\mathrm{H}_{2} \mathrm{O}_{2}$ relative to WT and VC in non-ABA treatment (Figure 11A). Abscisic acid significantly increased transcription of $A t R B O H D$ and $A t R B O H F$ genes in transgenic lines, which is in contrast to non-ABA conditions where it remained typically lower in transgenes than in WT and VC (Figure 11B).

\subsection{PeJRL Downregulated Synthesis of Endogenous $\mathrm{ABA}$ under $\mathrm{NaCl}$}

Under $\mathrm{NaCl}$ stress, abscisic acid (ABA) content in PeJRL-overexpressed plants was significantly lower than in WT Arabidopsis and VC (Figure 12A). In accordance, PeJRL-transgenic plants downregulated the expression of AtNCED2 and AtNCED9, two key enzymes in the biosynthesis of ABA under salt treatment (Figure 12B).

\subsection{PeJRL Altered Expression Profile of ABA-Mediated Salt Stress Responsive Genes}

To investigate whether PeJRL interacts with the ABA signalling network under salt stress, the expression levels of a subset of ABA-mediated salt stress responsive genes were examined in transgenic plants. These genes include ABF4/AREB2 [37], ABI5 [38], DREB1A, DREB2A [39], MYB2 [40], RD29A [41], RAB18 [42], SnRK2.2, and SnRK2.3 [24,43]. Most of the tested genes such as DREB1A, $D R E B 2 A, M Y B 2, R D 29 A$, and SNRK2.2 showed an increased transcript in PeJRL-transgenic lines (OE7 and OE23), compared with those in WT and vector controls (Figure 13). A few of the ABA-mediated stress-responsive genes (ABF4, $A B 15, R A B 18$, and $S n R K 2.3)$ remained unchanged or downregulated in transgenic plants (Figure 13). The upregulated $D R E B, M Y B, R D 29$ and SNRK may increase the plant sensitivity to ABA. 
A

$\mathrm{H}_{2} \mathrm{O}_{2}$

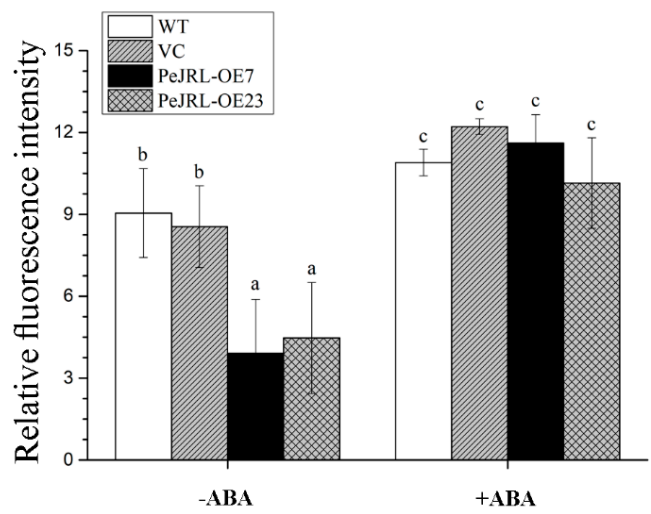

B

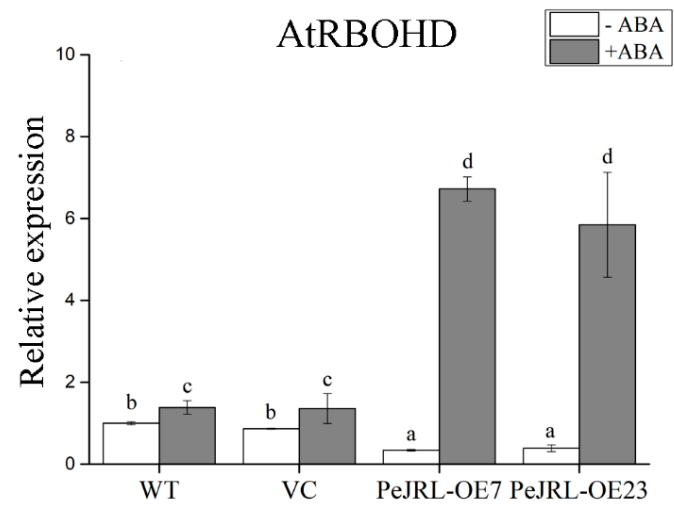

C

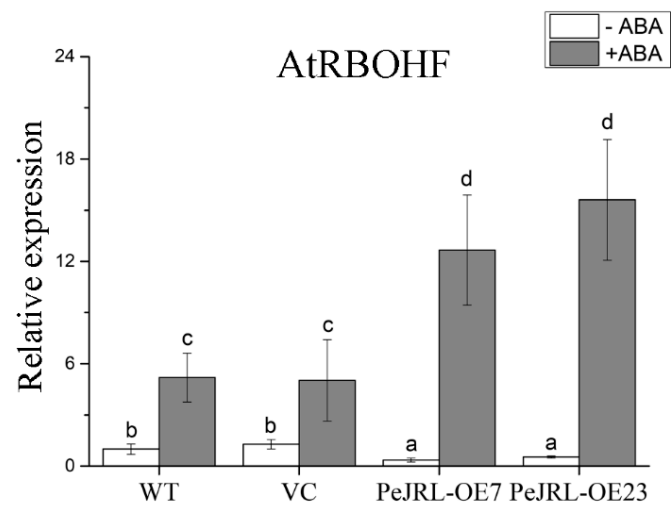

Figure 11. Effect of $A B A(5 \mu \mathrm{M}, 12 \mathrm{~h})$ on root $\mathrm{H}_{2} \mathrm{O}_{2}$ production and AtRBOHD and AtRBOHF expression in wild-type (WT) Arabidopsis, vector control (VC), and PeJRL-transgenic lines (OE7 and OE23) under $\mathrm{NaCl}$ stress. (A) $\mathrm{H}_{2} \mathrm{O}_{2}$ production. Seven-day-old seedlings were transferred to $1 / 2 \mathrm{MS}$ medium containing $125 \mathrm{mM} \mathrm{NaCl}$ supplemented without or with $5 \mu \mathrm{M}$ ABA for $12 \mathrm{~h}$. Seedlings were then incubated with $\mathrm{H}_{2}$ DCF-DA for $5 \mathrm{~min}$. Green fluorescence within cells was detected at the apical region of roots under a Leica confocal microscope. The mean fluorescence intensities of $\mathrm{H}_{2} \mathrm{DCF}-\mathrm{DA}$ are shown in control (-ABA) and ABA-treated roots (+ABA). (B) AtRBOHD and (C) AtRBOHF expression. AtRBOHD and AtRBOHF transcription were detected with RT-qPCR. The Arabidopsis AtACTIN2 was used as the internal control. Primers designed to target AtRBOHD, AtRBOHF, and AtACTIN2 genes are shown in Supplementary Materials Table S1. Each column corresponds to the mean of seven independent seedlings and columns labelled with different letters $(a-d)$ indicate significant differences at $p<0.05$. 
A

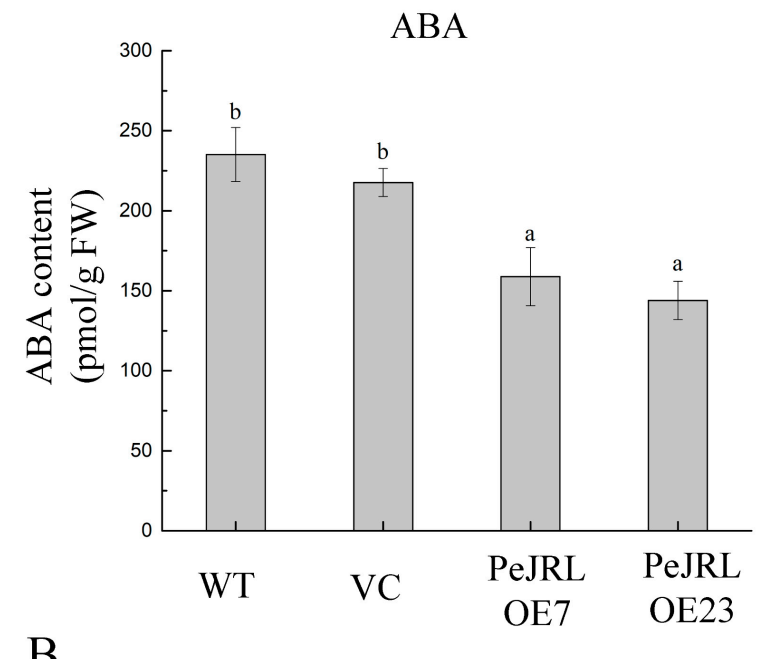

B

NCED

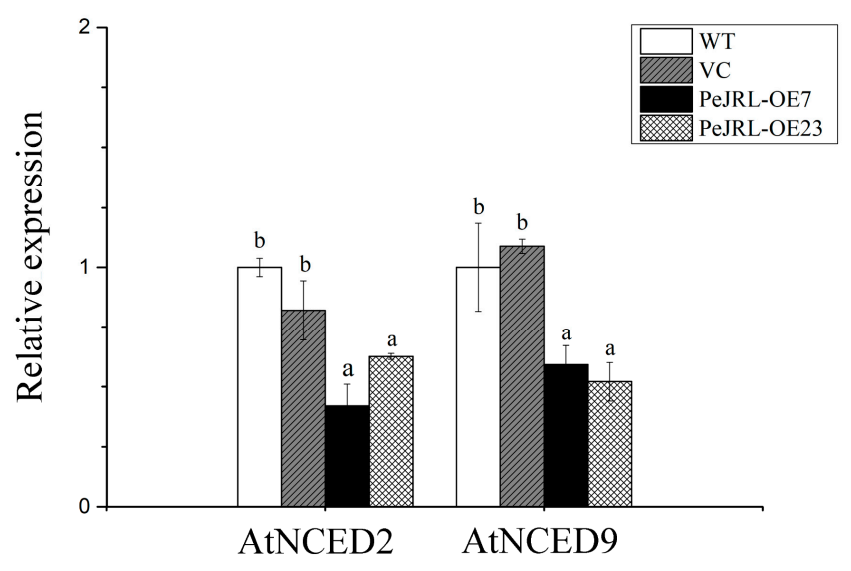

Figure 12. ABA content and expression of AtNCED2 and AtNCED9 in roots of wild-type (WT) Arabidopsis, vector control (VC), and PeJRL-transgenic lines (OE7 and OE23) under $\mathrm{NaCl}$ stress. Five-day-old seedlings were transferred to MS medium containing $75 \mathrm{mM} \mathrm{NaCl}$ for 10 days. (A) ABA content. ABA concentration was estimated using the enzyme-linked immunosorbent assay (ELISA) test. (B) Expression of AtNCED2 and AtNCED9. AtNCED2 and AtNCED9 transcription were detected with RT-qPCR. The Arabidopsis AtACTIN2 was used as the internal control. Primers designed to target AtNCED2, AtNCED9, and AtACTIN2 genes are shown in Supplementary Materials Table S1. Each column corresponds to the mean of seven independent seedlings and columns labelled with different letters $(\mathrm{a}, \mathrm{b})$ indicate significant differences at $p<0.05$. 


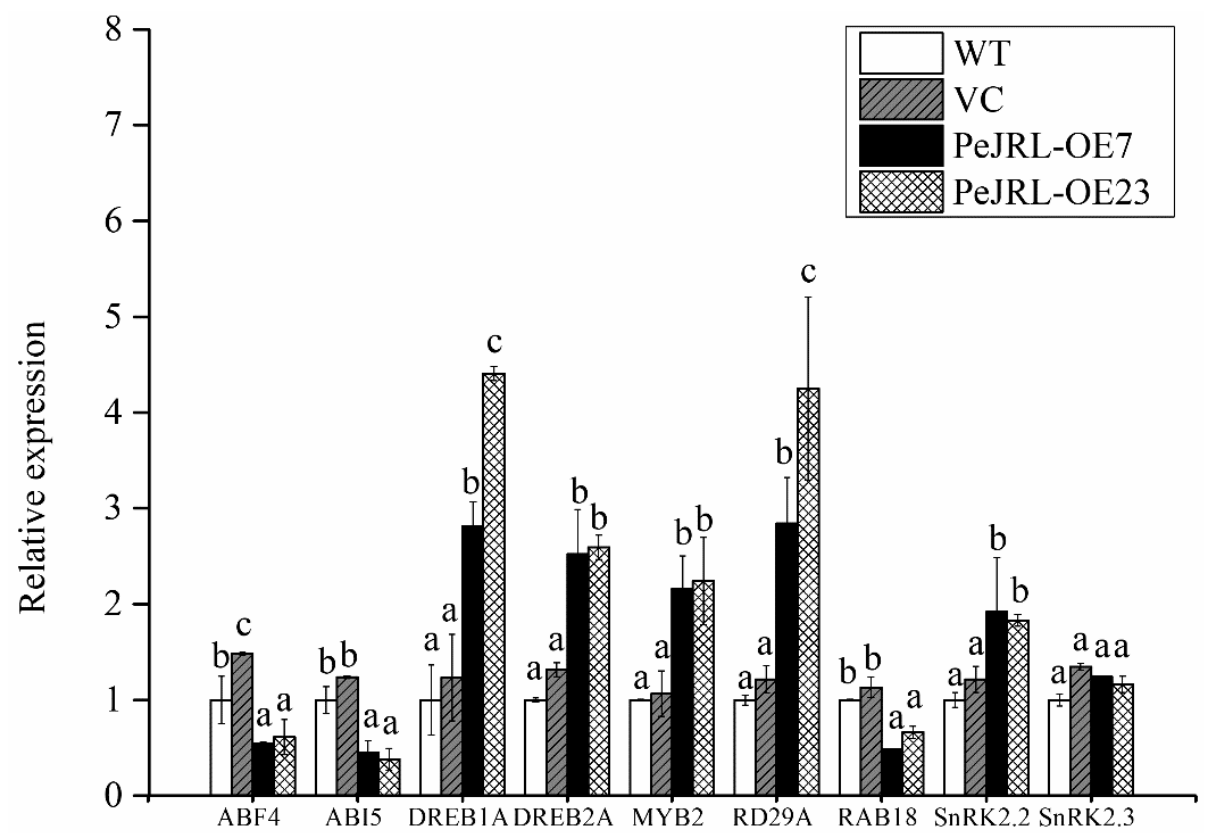

Figure 13. Expression level of ABA-mediated salt stress responsive genes in wild-type (WT) Arabidopsis, vector control (VC), and PeJRL-transgenic lines (OE7 and OE23) under salt stress. Five-day-old seedlings were transferred to MS medium containing $75 \mathrm{mM} \mathrm{NaCl}$ for 10 days. Transcription of ABA-mediated salt stress responsive genes was detected with RT-qPCR. The Arabidopsis AtACTIN2 was used as the internal control. Primers designed to target AtACTIN2 and ABA-mediated salt stress responsive genes are shown in Supplementary Materials Table S1. For each tested gene, each column corresponds to the mean of three independent replicates and columns labelled with different letters $(\mathrm{a}-\mathrm{c})$ indicate significant differences between $\mathrm{WT}, \mathrm{VC}$, and transgenic lines at $p<$ 0.05 .

\section{Discussion}

The present study confirmed the novel role of jacalin-related mannose-binding lectin in the salt response of P. euphratica. The PeJRL protein was shown to localize to the cytoplasmic region (Figure 3). Unexpectedly, we could not detect the nuclear localization, although PeJRL sequence showed a high similarity to orthologs of nucleocytoplasmic lectins in other plant species (Figure 2) [11]. Transcription analyses indicated that PeJRL was upregulated by $\mathrm{NaCl}$ in P. euphratica calli, leaves, and roots (Figure 1). Similarly, TaJRL26 was responsive to salt stress in wheat roots [16]. Salinity-stress induces the synthesis of a mannose-specific lectin in rice plants [19]. PeJRL overexpression in Arabidopsis significantly increased salt tolerance of transgenic plants, in terms of plant performance, primary root length, and membrane leakage during seedling establishments (Figures 4 and 5). Thus, it can be inferred that PeJRL contributes to salt adaptation in P. euphratica. Similarly, OsJRL overexpression in rice enhanced salt tolerance of transgenic plants [18]. Our data showed that the enhanced tolerance of Arabidopsis plants overexpressing PeJRL mainly resulted from the increased ability to regulate $\mathrm{K}^{+} / \mathrm{Na}^{+}$ and ROS homeostasis.

In PeJRL-overexpressed Arabidopsis, the enhancement of $\mathrm{NaCl}$ tolerance relied on, at least in part, the ability for $\mathrm{Na}^{+}$extrusion and $\mathrm{K}^{+}$maintenance (Figures 6 and 7). There was less $\mathrm{Na}^{+}$accumulation in root cells of transgenic plants (Figure 6) due to a higher ability for extruding $\mathrm{Na}^{+}$in root tips (Figure 7A). $\mathrm{Na}^{+}$extrusion is critical for plants adapting to salt stress environment $[7,8,20,28,30,32-34,44]$. Furthermore, we observed an apparent $\mathrm{H}^{+}$efflux in these salt-exposed roots (Figure $7 \mathrm{C}$ ). This indicates the activated $\mathrm{H}^{+}$-ATPases could establish an $\mathrm{H}^{+}$gradient across the $\mathrm{PM}$, thus promoting the exchange of $\mathrm{Na}^{+}$with $\mathrm{H}^{+}$[45]. In accordance, the expression of AtSOS1, AtAHA1, and ATAHA2 genes encoding $\mathrm{PM} \mathrm{Na}{ }^{+} / \mathrm{H}^{+}$antiporters and $\mathrm{H}^{+}$-ATPases were upward regulated in transgenic plants (Figure 7D). Therefore, in PeJRL-transgenic lines, the ion flux profiles and transcription data suggest that the 
$\mathrm{H}^{+}$-pumps contributed to $\mathrm{Na}^{+}$extrusion via increasing the antiport of $\mathrm{Na}^{+} / \mathrm{H}^{+}$across the plasma membrane $[30,31,46]$. In addition, the upregulation of $A t H K T$ under salt stress might also avoid excessive build-up of $\mathrm{Na}^{+}$in transgenic plants (Figure 7D). Under salt stress Arabidopsis high-affinity $\mathrm{K}^{+}$transporters (HKT) have been shown to mediate retrieval of $\mathrm{Na}^{+}$from the xylem, thus preventing excessive $\mathrm{Na}^{+}$in leaves [47-52]. Similarly, OsJRL-transgenic rice maintained higher transcript levels of three rice $H K T$ genes $(H K T 1 ; 3, H K T 1 ; 4$ and $H K T 1 ; 5)$ than the wild type under salinity treatment [18]. Collectively, these results showed that overexpression of $J R L$ genes could protect plant cells against $\mathrm{Na}^{+}$excess through upregulation of $\mathrm{Na}^{+}$transporter genes.

Furthermore, PeJRL-overexpression enabled transgenic plants to reduce the loss of $\mathrm{K}^{+}$under saline conditions, as compared to WT (Figure 7). It has been repeatedly shown that salt tolerance in plants is related to the capacity for maintaining $\mathrm{K}^{+}$homeostasis [30,33,34]. Salt-elicited loss of $\mathrm{K}^{+}$is through the $\mathrm{K}^{+}$channels activated by PM depolarization $[30,53,54]$. In PeJRL-overexpressed plants, the activated $\mathrm{H}^{+}$-ATPases restricted the membrane depolarization, thus reducing the channel-mediated $\mathrm{K}^{+}$loss under salt stress [30].

Under $\mathrm{NaCl}$ stress, PeJRL-transgenic plants displayed significantly lower $\mathrm{H}_{2} \mathrm{O}_{2}$ content than WT and VC (Figure 9). This is mainly the result of increased activity of CAT and POD, the main antioxidant enzyme scavenging $\mathrm{H}_{2} \mathrm{O}_{2}$ (Figure 8). In accordance, transcription of $C A T$ and $P O D$ was increased upon $\mathrm{NaCl}$ exposure in transgenic plants (Figure 8). The expression and activity of SOD significantly increased upon salt exposure, similar to the trend of CAT and POD (Figure 8). Superoxide dismutases are considered to be the first defence line against $\mathrm{O}_{2}{ }^{-}$and the reaction product $[55,56]$. In the present study, the coincident increase of SOD with CAT and POD in PeJRL-transgenes reveals an elevated capacity to detoxify both $\mathrm{O}_{2}{ }^{-}$and $\mathrm{H}_{2} \mathrm{O}_{2}$ that were caused by $\mathrm{NaCl}$, which is required for rapid removal of ROS and thus avoids oxidative damage [8]. In addition, we observed that PeJRL-overexpression limited the salt-induced expression of $A t R B O H D$ and AtRBOHF (Figure 9). This indicates that the transgenic plants could control the production of $\mathrm{O}_{2}{ }^{-}$via downregulation of NADPH oxidases under salt stress.

Unexpectedly, PeJRL overexpression lowered ABA content in salt-stressed Arabidopsis (Figure 12). This was due to the low transcripts of AtNCED2 and AtNCED9 (Figure 12), the two key enzymes in ABA biosynthesis [57-59]. It is noting to find that PeJRL increased ABA sensitivity in Arabidopsis in terms of plant performance, root length, and EL (Figure 10). Similarly, He et al. (2017) confirmed the increased ABA sensitivity in OsJRL transgenic rice [18]. We observed that a variety of ABA-mediated stress-responsive genes, such as DREB1A, DREB2A, MYB2, RD29A and SNRK2.2, showed an increased transcript in PeJRL-transgenic lines (Figure 13). The is in agreement with He et al. (2017), who found that ABA increased expression of genes encoding rice late embryogenesis abundant proteins (LEA19a, $L E A 23$, and LEA24), HKT ( $\mathrm{Na}^{+}$transporters, HKT1;3, HKT1;4, and HKT1;5), and DREB (DREB1A and $D R E B 2 B)$ [18]. Thus, it can be inferred that JRL interacts with ABA signalling network to regulate plant response to salt stress. Abscisic acid suppressed shoot length of rice plants, and the inhibition was more pronounced in OsJRL-overexpressing seedlings than wild type [18]. In our study, the ABA-induced increase of EL in transgenic Arabidopsis was presumably related to $\mathrm{H}_{2} \mathrm{O}_{2}$ production. Under $\mathrm{NaCl}$ salinity, ABA-induced increase of $\mathrm{H}_{2} \mathrm{O}_{2}$ was more pronounced in PeJRL-overexpressed plants (2.9and 2.3-fold), as compared to WT and VC (1.2- and 1.4-fold) (Figure 11). This is consistent to the drastic rise of $A t R B O H D$ and $A t R B O H F$ in salinized transgenic plants, while the expression of NADPH oxidase was less affected by combined treatment with $\mathrm{ABA}$ and $\mathrm{NaCl}$ in wild-type plants (Figure 11). Our data suggest that ABA-induced NADPH oxidase contributed to $\mathrm{H}_{2} \mathrm{O}_{2}$ production in salt-stressed plants. Therefore, $\mathrm{PeJRL}$-overexpressed plants decrease the ABA biosynthesis under $\mathrm{NaCl}$ stress, this is beneficial for salinized plants to control ROS homeostasis since $\mathrm{NaCl}$-elicited ABA caused a marked rise of $\mathrm{H}_{2} \mathrm{O}_{2}$. 


\section{Materials and Methods}

\subsection{Plant Materials and Treatments}

Populus euphratica seedlings (one-year-old, from the Xinjiang Uygur Autonomous Region, China) were cultured in a greenhouse at the experimental nursery of Beijing Forestry University as described previously [30,31]. Seedlings were raised for two months, then salinized with $\mathrm{NaCl}(200 \mathrm{mM}, 2 \mathrm{~L})$ in Hoagland's nutrient solution (full-strength). Leaves were sampled from upper shoots at $0,1,3,6,12$, 24,48 , and $72 \mathrm{~h}$. These leaves were immediately frozen in liquid $\mathrm{N}_{2}$, stored at a freezer $\left(-80{ }^{\circ} \mathrm{C}\right)$ for real-time quantitative PCR (RT-qPCR) assays.

Populus euphratica callus cultures were induced and sub-cultured every 15 days in the dark at $25^{\circ} \mathrm{C}[33,34]$. Ten days after transplantation onto new MS medium, P. euphratica cultures were subjected to $125 \mathrm{mM} \mathrm{NaCl}$ in liquid MS medium, and controls were cultured in liquid MS medium supplemented without $\mathrm{NaCl}$. Calluses were harvested after $0,3,12$, and $24 \mathrm{~h}$ of salt treatment, frozen, and stored at a freezer $\left(-80^{\circ} \mathrm{C}\right)$ for subsequent RNA isolation and RT-qPCR.

Surface-sterilized seeds of Arabidopsis thaliana (Columbia, Col-0) were plated on MS solid medium (half-strength) with the addition of sucrose $(1 \%, w / v)$ and Phytagel (0.24\%, Sigma-Aldrich). The seeds were stratified at $4{ }^{\circ} \mathrm{C}$ for 3 days before transferring to growth chambers with a $16 \mathrm{~h}$ photoperiod (150 $\mu \mathrm{mol} \mathrm{m} \mathrm{m}^{-2} \cdot \mathrm{s}^{-1}$ irradiation, $21^{\circ} \mathrm{C}, 80 \%$ relative humidity). Seven days after germination, seedlings were transplanted and grown at compost soil under a $16 \mathrm{~h}$ photoperiod in a growth chamber.

\subsection{Full-Length PeJRL Gene Cloning and Sequence Analysis}

Total RNA of P. euphratica leaves was isolated with EASYspin Plus Plant RNA Kit (AidLab, Beijing, China) based on the protocol instructions of manufacturer. The RNA ( $1 \mu \mathrm{g})$ was used as template to synthesize first-strand cDNA with oligo (dT) primer (Promega, Madison, WI, USA) and M-MLV Reverse Transcriptase (Promega, Madison, WI, USA) [45]. Full-length cDNA sequence of PeJRL was amplified with specific forward and reverse primers: 5'-ATGGCATCCTTGGAACGAATC-3', 5'-TTAGATTGTCGTCTCTGGTTTGAC-3'. The gel-purified PCR products were then ligated to the pMD18-T (Takara, Kusatsu, Japan) vector for DNA sequencing.

We compared the amino acid sequences of JRLs from different plant species with ClustalW (http:/ / www.genome.jp/tools/clustalw/, accessed on: 24 September 2018). Phylogenetic tree of JRL was constructed by the neighbour-joining method with 1000 bootstrap replicates using MEGA 5.2 software (http:/ / www.megasoftware.net/index.php, accessed on: 24 September 2018).

\subsection{Subcellular Localization Analysis}

Full-length cDNA was inserted into the modified pGreen0029-GFP vector between the HindIII and $\mathrm{XmaI}$ sites. PeJRL was fused upstream of the reporter gene, green fluorescent protein (GFP), under the control of the CaMV35S (cauliflower mosaic virus 35S) promoter. Protoplasts of Arabidopsis leaves were isolated and transformed using polyethylene glycol (PEG)-mediated protocol as per Yoo et al. (2007) [60]. The intensity of fluorescence was examined after incubation at $21^{\circ} \mathrm{C}$ for $16-20 \mathrm{~h}$. Confocal images were obtained with a confocal laser scanning microscope (Leica Microsystems $\mathrm{GmbH}$, Wetzlar, Germany) at 510-535 nm (for GFP fluorescence) and 650-750 nm (for chlorophyll fluorescence), respectively. The confocal parameters were set as described in previous studies: excitation wavelength was $488 \mathrm{~nm}$, and emission wavelength was 610-700 nm [61].

\subsection{Overexpression of PeJRL in Arabidopsis}

The full-length cDNA of PeJRL was cloned into pMDC85-the plant expression vector. Transcription of PeJRL was driven by the CaMV35S promoter. PeJRL: pMDC85 construct was transferred into Agrobacterium tumefaciens strain, GV3101, and then transformed into wild-type A. thaliana (Col-0 ecotype) [62]. The blank pMDC85 vector was introduced into wild-type $A$. thaliana (Col-0 ecotype) plants as a vector control (VC). Putative transgenic lines were screened on MS medium (half strength) 
supplemented with $25 \mathrm{mg} / \mathrm{L}$ hygromycin. To testify the transcription levels of the target gene, six homozygous lines (third generation) were selected according to the segregation ratio and verified by semi-quantitative reverse transcription PCR and RT-qPCR using PeJRL-specific primers (Supplementary Materials Table S1). Two independent transgenic lines, OE7 and OE23, which exhibited higher transcript abundance of $P e J R L$, were used for salt experiments.

\subsection{Quantitative PCR}

The expression of PeJRL in P. euphratica and transgenic Arabidopsis were analysed using RT-qPCR and semi-quantitative reverse-transcription PCR (RT-PCR), respectively. Total RNA was isolated respectively from control and $\mathrm{NaCl}$-treated P. euphratica leaves and Arabidopsis plants. The RNA isolation was performed as mentioned above. The RNase-free DNase (Promega, Madison, WI, USA) was used to eliminate the DNA in isolated RNA. The protocols for RT-PCR and RT-qPCR amplification were followed as per Han et al. [63] (2013) and Zhang et al. [64] (2017). House-keeping genes, AtACTIN2 and PeACTIN7, were used as internal controls for Arabidopsis and P. euphratica. Specific primers for target and house-keeping genes were listed in Supplementary Materials Table S1. Quantitative PCR amplifications were carried out in triplicate for each sample and experiments were repeated at least three times. The $\mathrm{Ct}$ value of the target gene was normalized with the $2^{-\Delta \Delta C T}$ method [65].

\subsection{Screening Tests for Salt Tolerance}

To determine germination efficiency for WT, VC, and transgenic lines, approximately 70 seeds for each genotype were sterilized with $\mathrm{NaClO}(5 \%, v / v)$ for $10 \mathrm{~min}$, then washed with sterile water 5 times. Seeds were plated on MS medium supplemented with 0,75 , or $125 \mathrm{mM} \mathrm{NaCl}$. These seeds were incubated at $4{ }^{\circ} \mathrm{C}$ for 3 days, then transferred to a growth chamber $\left(21^{\circ} \mathrm{C}\right)$ under a $16 \mathrm{~h} / 8 \mathrm{~h}$ (white light/dark) photoperiod. The seedling establishment was examined after 10 days of salt treatment.

Five-day-old seedlings of WT, VC, and transgenic lines grown on half-strength MS medium were used for the root-growth assay. These seedlings were treated with 0,75 or $125 \mathrm{mM} \mathrm{NaCl}$ on MS medium. After 10 days, primary root length was measured with ImageJ (Version 1.48, National Institutes of Health, Bethesda, Rockville Pike, MD, USA).

\subsection{Measurements Leaf Electrolyte Leakage}

Relative electrolyte leakage was measured using fresh leaves sampled from control and salinized plants. The collected leaves were placed in an Eppendorf tube and incubated in $4 \mathrm{~mL}$ of deionized water, then electrical conductance (EC) measured after $24 \mathrm{~h}$ incubation at room temperature. The final electrical conductance was measured after the samples were boiled for $30 \mathrm{~min}$ to induce complete leakage and cooled to room temperature [61]. The leaf electrolyte leakage was calculated followed the formula as follows:

$$
\mathrm{EL}(\%)=(\mathrm{EC} 1 / \mathrm{EC} 2) \times 100 \%
$$

where the EC1 is the initial electrical conductance of the leaves, EC2 represents the final electrical conductance.

\subsection{Detection of $\mathrm{Na}^{+}$Concentrations in Roots}

The concentrations of $\mathrm{Na}^{+}$in roots were detected with a sodium-specific dye, CoroNa-Green AM (Invitrogen, Carlsbad, CA, USA). Seedlings of WT, VC, and transgene lines (seven-day-old) were salinized with $\mathrm{NaCl}(0$ or $125 \mathrm{mM}$ ) for $12 \mathrm{~h}$ in $1 / 2 \mathrm{MS}$ liquid solution. Then roots were stained with the $\mathrm{Na}^{+}$probe in the dark for $2 \mathrm{~h}$, followed by washing with redistilled water (3-4 times). The fluorescence of CoroNa in root cells was visualized with a confocal microscope (Leica SP5, Microsystems GmbH, Wetzlar, German) with excitation wavelength at $488 \mathrm{~nm}$, and emission wavelength at 510-530 nm. The fluorescent intensity was calculated using ImageJ (Version 1.48, National Institutes of Health, Bethesda, Rockville Pike, MD, USA) [33-35,45]. 


\section{9. $\mathrm{H}_{2} \mathrm{O}_{2}$ Measurement and Expression of NADPH Oxidase}

The $\mathrm{H}_{2} \mathrm{O}_{2}$-specific fluorescent probe, $\mathrm{H}_{2}$ DCF-DA ( $2^{\prime}, 7^{\prime}$-dichlorodihydro-fluorescein diacetate; Molecular Probe, Eugene, OR, USA), was prepared in half-strength MS liquid solution ( $\mathrm{pH}$ 5.8) and used to detect $\mathrm{H}_{2} \mathrm{O}_{2}$ level in roots. Seedlings of WT, VC and transgenic lines (seven-day-old) were salinized without or with $125 \mathrm{mM} \mathrm{NaCl}$ for $12 \mathrm{~h}$. Then, roots were stained with $\mathrm{H}_{2}$ DCF-DA $(10 \mu \mathrm{M})$ in the dark for $5 \mathrm{~min}$. Thereafter, these $\mathrm{H}_{2}$ DCF-DA-loaded plants were washed three to four times with half-strength MS liquid solution. Fluorescence of $\mathrm{H}_{2}$ DCF-DA was detected with a Leica SP5 confocal microscope with excitation at $488 \mathrm{~nm}$ and emission at 510-530 $\mathrm{nm}$ [33-35].

The expression level of NADPH oxidase gene, AtRBOHD and AtRBOHF, was examined by RT-qPCR using the primers listed in Supplementary Materials Table S1.

\subsection{Root Flux Recordings and Transcription of Ion Homeostasis-Related Genes}

Wild-type, VC, and transgenic plants were grown on half-strength MS solid medium for seven days. Then these seedlings were transferred to MS medium and salinized without or with $125 \mathrm{mM}$ $\mathrm{NaCl}$ for $12 \mathrm{~h}$. Then roots were sampled and subjected to $30 \mathrm{~min}$ of equilibration in measuring solution containing the following components in $\mathrm{mM}: \mathrm{KCl}(0.5), \mathrm{CaCl}_{2}(0.1), \mathrm{MgCl}_{2}(0.1), \mathrm{NaCl}(0.1)$, and $2.5 \%$ sucrose ( $\mathrm{pH}$ of solution was adjusted to 5.8). Afterwards, steady-state fluxes of $\mathrm{Na}^{+}, \mathrm{K}^{+}$, and $\mathrm{H}^{+}$were measured continuously for $10 \mathrm{~min}$ at the meristematic zone (approximately $200 \mu \mathrm{m}$ from the tip). The meristematic zone usually exhibited larger flux rates than mature zones [66,67]. In this study, root flux rates were recorded with the Non-invasive Micro-Test Technique (NMT-YG-100, Younger USA LLC, Amherst, MA, USA) with ASET 2.0 (Sciencewares, Falmouth, MA, USA) and iFluxes 1.0 (Young-erUSA, LLC, Amherst, MA, USA) software, which is capable of integrating and coordinating differential voltage signal collection, motion control and image capture simultaneously. The ionic flux was measured by shifting the ion-selective microelectrode between two sites close the roots over a pre-set length (30 $\mu \mathrm{m}$ for intact roots in this experiment) at a frequency in the range of 0.3-0.5 Hz. Ionic flux was calculated by Fick's law of diffusion: $J=-D(d c / d x)$, where $J$ represents the ionic flux in the $x$ direction, $d c / d x$ is the ionic concentration gradient, and $D$ is the ionic diffusion constant $[30,31,45,66-68]$. The expression levels of $\mathrm{K}^{+} / \mathrm{Na}^{+}$homeostasis-related genes encoding plasma membrane $\mathrm{H}^{+}$-ATPases (AtAHA1 and AtAHA2), $\mathrm{Na}^{+} / \mathrm{H}^{+}$antiporter (AtSOS1), and high-affinity $\mathrm{K}^{+}$ transporter (AtHKT1) were analysed by RT-qPCR using the primers listed in Supplementary Materials Table S1.

\subsection{Activity Measurements and Transcriptional Assays of Antioxidant Enzymes}

For the enzymatic assays, transgenic seedlings, VC, and wild-type Arabidopsis (0.2 g) were frozen in liquid $\mathrm{N}_{2}$, ground to a fine powder, and then homogenized in $2 \mathrm{~mL}$ ice-cold potassium phosphate buffer (50 mM, pH 7.0) supplemented with poly(vinylpyrrolidone) (PVP) (1\%), ethylenediaminetetraacetic acid (EDTA) $(1 \mathrm{mM})$, and ascorbate acid (AsA) (1 mM). After centrifugation at $12,000 \times g$ for $20 \mathrm{~min}\left(\right.$ at $4{ }^{\circ} \mathrm{C}$ ) the supernatants were used to measure the activity of antioxidant enzymes, including superoxide dismutase (SOD), catalase (CAT), and peroxidase (POD). Total activity of these enzymes was determined as described previously [6,69-72]. In addition, the expression of CAT, POD, and SOD were analysed by RT-qPCR (Supplementary Materials Table S1).

\subsection{Determination of $A B A$ Content and Expression of $A B A$ Biosynthesis Genes}

Five-day-old seedlings of transgenic, VC, and wild-type Arabidopsis were transferred to MS medium containing $75 \mathrm{mM} \mathrm{NaCl}$ for 10 days. Then Arabidopsis seedlings were sampled, frozen in liquid nitrogen, and homogenized in phosphate buffered saline (PBS, pH7.4). The homogenate was centrifuged at $3000 \times g$ for $20 \mathrm{~min}$, and the supernatants were used to detect the level of endogenous ABA. Endogenous ABA level was measured in the supernatant using ELISA (MLBIO, Shanghai, China). 
The expression levels of ABA biosynthesis genes, AtNCED2 and AtNCED9, were analysed by RT-qPCR (Supplementary Table S1).

\subsection{ABA Tests for Transgenic Lines}

Seed germination and seedling establishment for transgenic lines and wild-type were determined under ABA treatment. In brief, seeds for each genotype were sterilized with $5 \% \mathrm{NaClO}(v / v)$ for $10 \mathrm{~min}$, then washed with sterile water for 5 times. Seeds were germinated on MS medium containing 0, 0.6, or $5 \mu \mathrm{M}$ ABA. After seed stratification, the seeds were transferred to a growth chamber $\left(21^{\circ} \mathrm{C}\right)$ under a $16 \mathrm{~h} / 8 \mathrm{~h}$ (white light/dark) photoperiod, and then plant performance was examined after 10 days of ABA treatment. For root length and EL measurements, five-day-old seedlings grown on half-strength MS medium were transferred to MS medium supplemented with $0,0.6$, or $5 \mu \mathrm{M} A B A$, respectively. Primary root length was measured with Image 1.48 (National Institutes of Health, Bethesda, Rockville Pike, MD, USA) after 10 days of treatment. Electrolyte leakage of ABA-treated plants was measured as described above.

Seven-day-old seedlings were transferred to $1 / 2 \mathrm{MS}$ medium containing $125 \mathrm{mM} \mathrm{NaCl}$ supplemented without or with $5 \mu \mathrm{M}$ ABA for $12 \mathrm{~h}$. Seedlings were then incubated with $\mathrm{H}_{2}$ DCF-DA $(10 \mu \mathrm{M})$ for $5 \mathrm{~min}$. Green fluorescence within cells was detected at the apical region of roots under a Leica confocal microscope. AtRBOHD and AtRBOHF transcription were detected with RT-qPCR. The Arabidopsis AtACTIN2 was used as the internal control. Primers designed to target AtRBOHD, AtRBOHF, and AtACTIN2 genes are shown in Supplementary Materials Table S1.

\subsection{The Expression of ABA-Mediated Salt Stress Responsive Genes}

Wild-type, VC, and transgenic lines were grown on half-strength MS medium for five days. Then these seedlings were treated with $75 \mathrm{mM} \mathrm{NaCl}$ for 10 days on MS medium. Total RNA was extracted and used for the RT-qPCR assays (see above). The primers target to ABF4, AREB2, ABI5, DREB1A, DREB2A, MYB2, RD29A, RAB18, SnRK2.2, and SnRK2.3 were listed in Supplementary Materials Table S1.

\subsection{Data Analysis}

All experiments were repeated at least three times with consistent results. The data were subjected to SPSS (version 19.0, IBM Corporation, Armonk, NY, USA) for statistical analysis. Statistical analyses were performed using one-way ANOVA. Unless otherwise stated, a $p$-value less than 0.05 was considered statistically significant.

\section{Conclusions}

Salt treatment induced expression of a jacalin-related mannose-binding lectin, $J R L$, in P. euphratica. $P e J R L$ overexpression contributed to salinity tolerance in Arabidopsis. A schematic model was proposed to show the mediation of PeJRL on ionic and ROS homeostasis (Figure 14). PeJRL upward-regulated activity of $\mathrm{PM} \mathrm{H}^{+}$-pumps and $\mathrm{Na}^{+} / \mathrm{H}^{+}$antiporters, thus promoted the $\mathrm{Na}^{+}$extrusion. Furthermore, the activated $\mathrm{H}^{+}$-pumps preserved a less-depolarized membrane potential, which restrained the $\mathrm{K}^{+}$ loss through $\mathrm{K}^{+}$channels in the PM [30]. In addition, the high-affinity $\mathrm{K}^{+}$transporter, AtHKT1, might contribute to the avoidance of excessive accumulation of $\mathrm{Na}^{+}$under salt stress. The PeJRL maintained ROS homeostasis by activating the antioxidant enzymes, and meanwhile repressing ABA biosynthesis, thus reduced the ABA-elicited ROS production and the oxidative damage during the period of salt stress. 


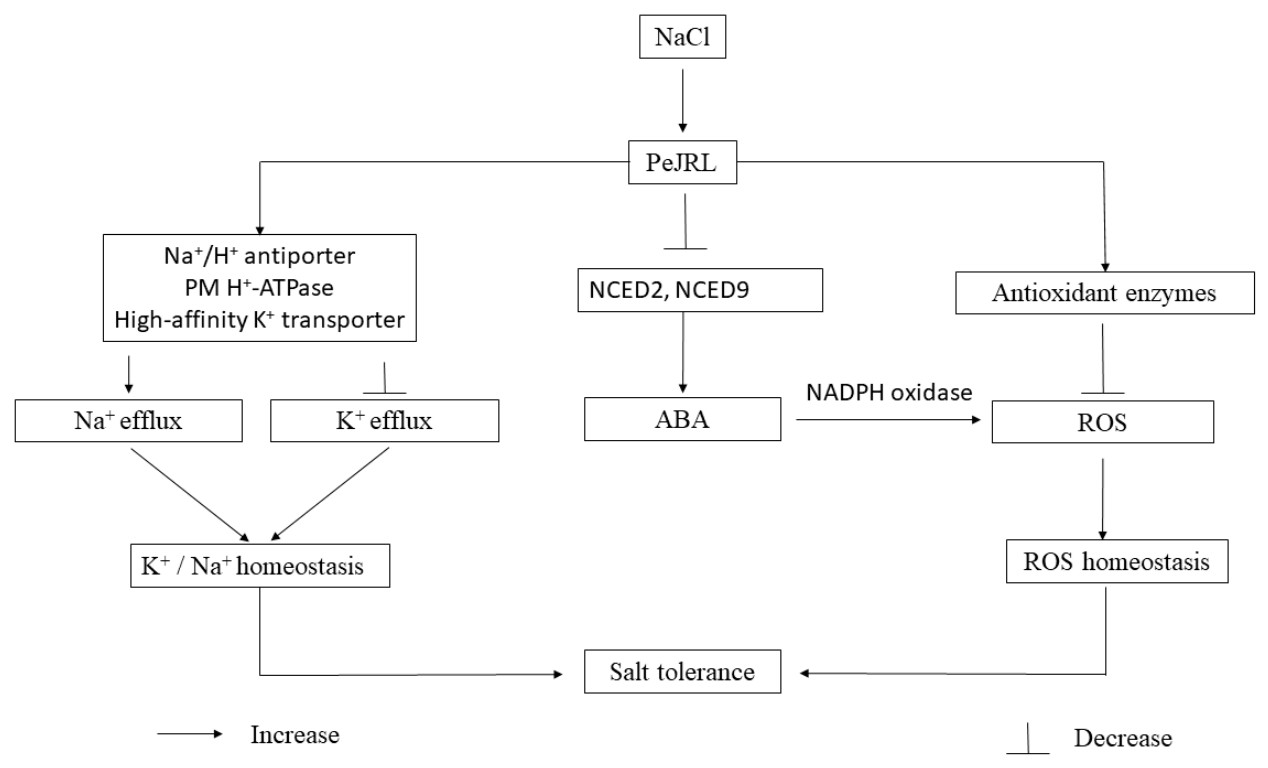

Figure 14. A schematic model showing mediation of Populus euphratica JRL in plant response to salt stress.

Supplementary Materials: Supplementary materials can be found at http:/ /www.mdpi.com/1422-0067/20/4/ $815 /$ s1.

Author Contributions: H.Z., C.D., and S.C. conceived of the original research project and selected methods. S.C. supervised the experiments. H.Z., C.D., J.Y., Y.-L.Z., Y.-N.Z., S.D., N.Z., and G.S. performed most of the experiments. X.Z., C.L., S.L., and R.Z. provided technical assistance to H.Z., C.D., J.Y., Y.-L.Z., Y.-N.Z., S.D., N.Z., and G.S., H.Z. and C.D. designed the experiments and analysed the data. H.Z. refined the project and wrote the manuscript with contributions from all the authors. R.Z. and S.C. revised the writing. All authors have read and approved the manuscript.

Funding: This research was supported jointly by National Natural Science Foundation of China (grant nos. 31770643 and 31570587), Beijing Municipal Natural Science Foundation (grant nos. 6182030 and 6172024), the Program of Introducing Talents of Discipline to Universities (111 Project, grant no. B13007), and Fundamental Research Funds for the Central Universities (2017ZY07).

Conflicts of Interest: The authors declare that the research was conducted in the absence of any commercial or financial relationships that could be construed as a potential conflict of interest.

\section{Abbreviations}

$\begin{array}{ll}\text { ABA } & \text { abscisic acid } \\ \text { JRL } & \text { jacalin-related mannose-binding lectin } \\ \text { ORF } & \text { open reading frame } \\ \text { H}_{2} \text { DCF-DA } & 2^{\prime}, 7^{\prime} \text {-dichlorodihydro-fluorescein diacetate } \\ \text { NCED } & \text { 9-cis-epoxycarotenoid dioxygenase } \\ \text { MS } & \text { Murashige-Skoog medium } \\ \text { NADPH } & \text { reduced nicotinamide adenine dinucleotide phosphate } \\ \text { mJRL } & \text { mannose-specific jacalin related lectin } \\ \text { NMT } & \text { non-invasive micro-test technique } \\ \text { RT-qPCR } & \text { quantitative reverse transcription pcr } \\ \text { RBOH } & \text { respiratory burst oxidase homolog protein } \\ \text { ROS } & \text { reactive oxygen species } \\ \text { SOS } & \text { salt overly sensitive } \\ \text { SOD } & \text { superoxide dismutase } \\ \text { CAT } & \text { catalase } \\ \text { POD } & \text { peroxidase } \\ \text { PM } & \text { plasma membrane } \\ \text { EL } & \text { electrolyte leakage }\end{array}$




\section{References}

1. Zhu, J.K. Cell signaling under salt, water and cold stresses. Curr. Opin. Plant Biol. 2001, 4, 401-406. [CrossRef]

2. Zhu, J.K. Regulation of ion homeostasis under salt stress. Curr. Opin. Plant Biol. 2003, 6, 441-445. [CrossRef]

3. Munns, R.; Tester, M. Mechanisms of salinity tolerance. Annu. Rev. Plant Biol. 2008, 59, 651-681. [CrossRef] [PubMed]

4. Tuteja, N. Mechanisms of high salinity tolerance in plants. Methods Enzymol. 2007, 428, 419-438. [PubMed]

5. Wang, R.G.; Chen, S.L.; Deng, L.; Fritz, E.; Hüttermann, A.; Polle, A. Leaf photosynthesis, fluorescence response to salinity and the relevance to chloroplast salt compartmentation and antioxidative stress in two poplars. Trees 2007, 21, 581-591. [CrossRef]

6. Wang, R.G.; Chen, S.L.; Zhou, X.Y.; Shen, X.; Deng, L.; Zhu, H.J.; Shao, J.; Shi, Y.; Dai, S.X.; Fritz, E.; et al. Ionic homeostasis and reactive oxygen species control in leaves and xylem sap of two poplars subjected to $\mathrm{NaCl}$ stress. Tree Physiol. 2008, 28, 947-957. [CrossRef] [PubMed]

7. Ding, M.Q.; Hou, P.C.; Shen, X.; Wang, M.J.; Deng, S.R.; Sun, J.; Wang, R.G.; Zhou, X.Y.; Lu, C.F.; Zhang, D.Q.; et al. Salt-induced expression of genes related to $\mathrm{Na}^{+} / \mathrm{K}^{+}$and ROS homeostasis in leaves of salt-resistant and salt-sensitive poplar species. Plant Mol. Biol. 2010, 73, 251-269. [CrossRef]

8. Chen, S.L.; Polle, A. Salinity tolerance of Populus. Plant Biol. 2010, 12, 317-333. [CrossRef]

9. Polle, A.; Chen, S.L. On the salty side of life: Molecular, physiological and anatomical adaptation and acclimation of trees to extreme habitats. Plant Cell Environ. 2015, 38, 1794-1816. [CrossRef]

10. Damme, E.J.M.V.; Peumans, W.J.; Barre, A.; Rougã, P. Plant Lectins: A composite of several distinct families of structurally and evolutionary related proteins with diverse biological roles. Crit. Rev. Plant Sci. 1998, 17, 575-692. [CrossRef]

11. Lannoo, N.; Vandenborre, G.; Miersch, O.; Smagghe, G.; Wasternack, C.; Peumans, W.J.; Damme, E.J.M. The jasmonate-induced expression of the Nicotiana tabacum leaf lectin. Plant Cell Physiol. 2007, 48, 1207-1218. [CrossRef] [PubMed]

12. Chrispeels, M.J.; Raikhel, N.V. Lectins, lectin genes and their role in plant defense. Plant Cell 1991, 3, 1-9. [CrossRef] [PubMed]

13. Tinjuangjun, P.; Loc, N.T.; Amr, G.; Gatehouse, J.A.; Christou, P. Enhanced insect resistance in Thai rice varieties generated by particle bombardment. Mol. Breed. 2006, 391-399.

14. Saha, P.; Dasgupta, I.; Das, S. A novel approach for developing resistance in rice against phloem limited viruses by antagonizing the phloem feeding hemipteran vectors. Plant Mol. Biol. 2006, 62, 735-752. [CrossRef] [PubMed]

15. Xiang, Y.; Song, M.; Wei, Z.Y.; Tong, J.H.; Zhang, L.X.; Xiao, L.T.; Ma, Z.Q.; Wang, Y. A jacalin-related lectin-like gene in wheat is a component of the plant defence system. J. Exp. Bot. 2011, 62, 5471-5483. [CrossRef] [PubMed]

16. Song, M.; Xu, W.Q.; Xiang, Y.; Jia, H.Y.; Zhang, L.X.; Ma, Z.Q. Association of jacalin-related lectins with wheat responses to stresses revealed by transcriptional profiling. Plant Mol. Biol. 2014, 84, 95-110. [CrossRef] [PubMed]

17. Hirano, K.; Teraoka, T.; Yamanaka, H.; Harashima, A.; Kunisaki, A.; Takahashi, H.; Hosolawa, D. Novel mannose-binding rice lectin composed of some isolectins and its relation to a stress-inducible salT gene. Plant Cell Physiol. 2000, 41, 258-267. [CrossRef]

18. He, X.; Li, L.; Xu, H.; Xi, J.; Cao, X.; Xu, H.; Rong, S.; Dong, Y.; Wang, C.; Chen, R.; et al. A rice jacalin-related mannose-binding lectin gene, OsJRL, enhances Escherichia coli viability under high salinity stress and improves salinity tolerance of rice. Plant Biol. 2017, 19, 257-267. [CrossRef]

19. Zhang, W.; Peumans, W.J.; Barre, A.; Astoul, C.H.; Rovira, P.; Rougé, P.; Proost, P.; Truffa-Bachi, P. Isolation and characterization of a jacalin-related mannose-binding lectin from salt-stressed rice (Oryza sativa) plants. Planta 2000, 210, 970-978.

20. Chen, S.L.; Li, J.; Wang, S.; Hüttermann, A.; Altman, A. Salt, nutrient uptake and transport, and ABA of Populus euphratica; a hybrid in response to increasing soil NaCl. Trees 2001, 15, 186-194. [CrossRef]

21. Finkelstein, R.R.; Gampala, S.S.L.; Rock, C.D. Abscisic acid signaling in seeds and seedlings. Plant Cell 2002, 14, S15-S45. [CrossRef] [PubMed] 
22. Adie, B.A.T.; Pérez-Pérez, J.; Pérez-Pérez, M.M.; Godoy, M.; Sánchez-Serrano, J.J.; Schmelz, E.A.; Solano, R. ABA is an essential signal for plant resistance to pathogens affecting JA biosynthesis and the activation of defenses in Arabidopsis. Plant Cell 2007, 19, 1665-1681. [CrossRef] [PubMed]

23. Cutler, S.R.; Rodriguez, P.L.; Finkelstein, R.R.; Abrams, S.R. Abscisic acid: Emergence of a core signaling network. Annu. Rev. Plant Biol. 2010, 61, 651-679. [CrossRef] [PubMed]

24. Fujita, Y.; Fujita, M.; Shinozaki, K.; Yamaguchi-Shinozaki, K. ABA-mediated transcriptional regulation in response to osmotic stress in plants. J. Plant Res. 2011, 124, 509-525. [CrossRef] [PubMed]

25. Shakirova, F.M.; Bezrukova, M.V.; Shayakhmetov, I.F. Effect of temperature shock on the dynamics of abscisic acid and wheat germ agglutinin accumulation in wheat cell culture. Plant Growth Regul. 1996, 19, 85-87. [CrossRef]

26. Chen, S.L.; Li, J.K.; Fritz, E.; Wang, S.S.; Hüttermann, A. Sodium and chloride distribution in roots and transport in three poplar genotypes under increasing $\mathrm{NaCl}$ stress. For. Ecol. Manag. 2002, 168, 217-230. [CrossRef]

27. Chen, S.L.; Li, J.K.; Wang, T.H.; Wang, S.S.; Polle, A.; Hüttermann, A. Osmotic stress and ion-specific effects on xylem abscisic acid and the relevance to salinity tolerance in poplar. J. Plant Growth Regul. 2002, 21, 224-233. [CrossRef]

28. Chen, S.L.; Li, J.K.; Wang, S.S.; Fritz, E.; Hüttermann, A.; Altman, A. Effects of NaCl on shoot growth, transpiration, ion compartmentation, and transport in regenerated plants of Populus euphratica and Populus tomentosa. Can. J. For. Res. 2003, 33, 967-975. [CrossRef]

29. Ottow, E.A.; Brinker, M.; Teichmann, T.; Fritz, E.; Kaiser, W.; Brosche, M.; Kangasjarvi, J.; Jiang, X.N.; Polle, A. Populus euphratica displays apoplastic sodium accumulation, osmotic adjustment by decreases in calcium and soluble carbohydrates, and develops leaf succulence under salt stress. Plant Physiol. 2005, 139, 1762-1772. [CrossRef]

30. Sun, J.; Dai, S.X.; Wang, R.G.; Chen, S.L.; Li, N.Y.; Zhou, X.Y.; Lu, C.F.; Shen, X.; Zheng, X.J.; Hu, Z.M.; et al. Calcium mediates root $\mathrm{K}^{+} / \mathrm{Na}^{+}$homeostasis in poplar species differing in salt tolerance. Tree Physiol. 2009, 29, 1175-1186. [CrossRef]

31. Sun, J.; Chen, S.L.; Dai, S.X.; Wang, R.G.; Li, N.Y.; Shen, X.; Zhou, X.Y.; Lu, C.F.; Zheng, X.J.; Hu, Z.M.; et al. $\mathrm{NaCl}$-induced alternations of cellular and tissue ion fluxes in roots of salt-resistant and salt-sensitive poplar species. Plant Physiol. 2009, 149, 1141-1153. [CrossRef] [PubMed]

32. Ma, X.Y.; Deng, L.; Li, J.K.; Zhou, X.Y.; Li, N.Y.; Zhang, D.C.; Lu, Y.J.; Wang, R.G.; Sun, J.; Lu, C.F.; et al. Effect of $\mathrm{NaCl}$ on leaf $\mathrm{H}^{+}$-ATPase and the relevance to salt tolerance in two contrasting poplar species. Trees Struct. Funct. 2010, 24, 597-607. [CrossRef]

33. Sun, J.; Wang, M.J.; Ding, M.Q.; Deng, S.R.; Liu, M.Q.; Lu, C.F.; Zhou, X.Y.; Shen, X.; Zheng, X.J.; Zhang, Z.K.; et al. $\mathrm{H}_{2} \mathrm{O}_{2}$ and cytosolic $\mathrm{Ca}^{2+}$ signals triggered by the $\mathrm{PM} \mathrm{H}^{+}$-coupled transport system mediate $\mathrm{K}^{+} / \mathrm{Na}^{+}$ homeostasis in NaCl-stressed Populus euphratica cells. Plant Cell Environ. 2010, 33, 943-958. [CrossRef] [PubMed]

34. Sun, J.; Li, L.S.; Liu, M.Q.; Wang, M.J.; Ding, M.Q.; Deng, S.R.; Lu, C.F.; Zhou, X.Y.; Shen, X.; Zheng, X.J.; et al. Hydrogen peroxide and nitric oxide mediate $\mathrm{K}^{+} / \mathrm{Na}^{+}$homeostasis and antioxidant defense in $\mathrm{NaCl}$-stressed callus cells of two contrasting poplars. Plant Cell Tissue Organ Cult. 2010, 103, 205-215. [CrossRef]

35. Sun, J.; Zhang, X.; Deng, S.R.; Zhang, C.L.; Wang, M.J.; Ding, M.Q.; Zhao, R.; Shen, X.; Zhou, X.Y.; Lu, C.F.; et al. Extracellular ATP signaling is mediated by $\mathrm{H}_{2} \mathrm{O}_{2}$ and cytosolic $\mathrm{Ca}^{2+}$ in the salt response of Populus euphratica cells. PLoS ONE 2012, 7, e53136. [CrossRef] [PubMed]

36. Brinker, M.; Brosché, M.; Vinocur, B.; Abo-Ogiala, A.; Fayyaz, P.; Janz, D.; Ottow, E.A.; Cullmann, A.D.; Saborowski, J.; Kangasjärvi, J.; et al. Linking the salt transcriptome with physiological responses of a salt-resistant Populus species as a strategy to identify genes important for stress acclimation. Plant Physiol. 2010, 154, 1697-1709. [CrossRef] [PubMed]

37. Choi, H.; Hong, J.; Ha, J.; Kang, J.; Kim, S.Y. ABFs, a family of ABA-responsive element binding factors. J. Biol. Chem. 2000, 275, 1723-1730. [CrossRef] [PubMed]

38. Finkelstein, R.R.; Lynch, T.J. The Arabidopsis abscisic acid response gene $A B I 5$ encodes a basic leucine zipper transcription factor. Plant Cell 2000, 12, 599-609. [CrossRef] 
39. Liu, Q.; Kasuga, M.; Sakuma, Y.; Abe, H.; Miura, S.; Yamaguchi-Shinozaki, K.; Shinozaki, K. Two transcription factors, DREB1 and DREB2, with an EREBP/AP2 DNA binding domain separate two cellular signal transduction pathways in drought- and low-temperature-responsive gene expression, respectively, in Arabidopsis. Plant Cell 1998, 10, 1391-1406. [CrossRef]

40. Abe, H.; Urao, T.; Ito, T.; Seki, M.; Shinozaki, K.; Yamaguchishinozaki, K. Arabidopsis AtMYC2 (bHLH) and AtMYB2 (MYB) function as transcriptional activators in abscisic acid signaling. Plant Cell 2003, 15, 63-78. [CrossRef]

41. Yamaguchishinozaki, K.; Shinozaki, K. A novel cis-acting element in an Arabidopsis gene is involved in responsiveness to drought, low-temperature, or high-salt stress. Plant Cell 1994, 6, 251-264.

42. Lång, V.; Palva, E.T. The expression of a rab-related gene, rab18, is induced by abscisic acid during the cold acclimation process of Arabidopsis thaliana (L.) Heynh. Plant Mol. Boil. 1992, 20, 951-962.

43. Fujii, H.; Verslues, P.E.; Zhu, J.K. Identification of two protein kinases required for abscisic acid regulation of seed germination, root growth, and gene expression in Arabidopsis. Plant Cell 2007, 19, 485-494. [CrossRef] [PubMed]

44. Shi, H.; Ishitani, M.; Kim, C.; Zhu, J.K. The Arabidopsis thaliana salt tolerance gene SOS1 encodes a putative $\mathrm{Na}^{+} / \mathrm{H}^{+}$antiporter. Proc. Natl. Acad. Sci. USA. 2000, 97, 6896-6901. [CrossRef] [PubMed]

45. Wang, M.J.; Wang, Y.; Sun, J.; Ding, M.Q.; Deng, S.R.; Hou, P.C.; Ma, X.J.; Zhang, Y.H.; Wang, F.F.; Sa, G.; et al. Overexpression of PeHA1 enhances hydrogen peroxide signaling in salt-stressed Arabidopsis. Plant Physiol. Biochem. 2013, 71, 37-48. [CrossRef] [PubMed]

46. Qiu, Q.S.; Guo, Y.; Dietrich, M.A.; Schumaker, K.S.; Zhu, J.K. Regulation of SOS1, a plasma membrane $\mathrm{Na}^{+} / \mathrm{H}^{+}$exchanger in Arabidopsis thaliana, by SOS 2 and $\mathrm{SOS}_{3}$. Proc. Natl. Acad. Sci. USA. 2002, 99, 8436-8441. [CrossRef]

47. Uozumi, N.; Kim, E.J.; Rubio, F.; Yamaguchi, T.; Muto, S.; Tsuboi, A.; Bakker, E.P.; Nakamura, T.; Schroeder, J.I. The Arabidopsis HKT1 gene homolog mediates inward $\mathrm{Na}^{+}$currents in Xenopus laevis oocytes and $\mathrm{Na}^{+}$uptake in Saccharomyces cerevisiae. Plant Physiol. 2000, 122, 1249-1259. [CrossRef]

48. Rus, A.; Lee, B.H.; Munoz-Mayor, A.; Sharkhuu, A.; Miura, K.; Zhu, J.K.; Bressan, R.A.; Hasegawa, P.M. AtHKT1 facilitates $\mathrm{Na}^{+}$homeostasis and $\mathrm{K}^{+}$nutrition in planta. Plant Physiol. 2004, 136, 2500-2511. [CrossRef]

49. Kader, M.A.; Seidel, T.; Golldack, D.; Lindberg, S. Expressions of OsHKT1, OsHKT2, and OsVHA are differentially regulated under $\mathrm{NaCl}$ stress in salt-sensitive and salt-tolerant rice (Oryza sativa L.) cultivars. J. Exp. Bot. 2006, 57, 4257-4268. [CrossRef]

50. Plett, D.; Safwat, G.; Gilliham, M.; Møller, I.S.; Roy, S.; Shirley, N.; Jacobs, A.; Johnson, A.; Tester, M. Improved salinity tolerance of rice through cell type-specific expression of AtHKT1;1. PLoS ONE 2010, 5, e12571. [CrossRef]

51. Damien, P.J.; Egdane, J.A.; Ismail, A.M. Salinity tolerance, $\mathrm{Na}^{+}$exclusion and allele mining of $H K T 1 ; 5$ in Oryza sativa and O. glaberrima: many sources, many genes, one mechanism. BMC Plant Biol. 2013, 13, 1-16.

52. Schroeder, J.I.; Delhaize, E.; Frommer, W.B.; Guerinot, M.L.; Harrison, M.J.; Herrera-Estrella, L.; Horie, T.; Kochian, L.V.; Munns, R.; Nishizawa, N.K.; et al. Using membrane transporters to improve crops for sustainable food production. Nature 2013, 497, 60-66. [CrossRef] [PubMed]

53. Chen, Z.H.; Pottosin, I.I.; Cuin, T.A.; Fuglsang, A.T.; Tester, M.; Jha, D.; Jazo-Zepeda, I.; Zhou, M.X.; Palmgren, M.G.; Newman, I.A.; et al. Root plasma membrane transporters controlling $\mathrm{K}^{+} / \mathrm{Na}^{+}$homeostasis in salt-stressed barley. Plant Physiol. 2007, 145, 1714-1725. [CrossRef] [PubMed]

54. Shabala, S.; Cuin, T.A. Potassium transport and plant salt tolerance. Physiol. Plant. 2008, 133, 651-669. [CrossRef] [PubMed]

55. Bowler, C.; Van Montagu, M.V.; Inzé, D. Superoxide dismutase and stress tolerance. Annu. Rev. Plant Biol. 1992, 43, 83-116. [CrossRef]

56. Fridovich, I. Superoxide radical and superoxide dismutases. Annu. Rev. Biochem. 1995, 64, 97-112. [CrossRef] [PubMed]

57. Tan, B.C.; Joseph, L.M.; Deng, W.T.; Liu, L.; Li, Q.B.; Cline, K.; Mccarty, D.R. Molecular characterization of the Arabidopsis 9-cis epoxycarotenoid dioxygenase gene family. Plant J. 2003, 35, 44-56. [CrossRef]

58. Nambara, E.; Marion-Poll, A. Abscisic acid biosynthesis and catabolism. Annu. Rev. Plant Biol. 2005, 56, 165-185. [CrossRef] [PubMed] 
59. Seo, M.; Kanno, Y.; Frey, A.; North, H.M.; Marion-Poll, A. Dissection of Arabidopsis NCED9 promoter regulatory regions reveals a role for ABA synthesized in embryos in the regulation of GA-dependent seed germination. Plant Sci. 2016, 246, 91-97. [CrossRef] [PubMed]

60. Yoo, S.D.; Cho, Y.H.; Sheen, J. Arabidopsis mesophyll protoplasts: A versatile cell system for transient gene expression analysis. Nat. Protoc. 2007, 2, 1565-1572. [CrossRef] [PubMed]

61. Deng, S.R.; Sun, J.; Zhao, R.; Ding, M.Q.; Zhang, Y.N.; Sun, Y.L.; Wang, W.; Tan, Y.Q.; Liu, D.D.; Ma, X.J.; et al. Populus euphratica APYRASE2 enhances cold tolerance by modulating vesicular trafficking and extracellular ATP in Arabidopsis plants. Plant Physiol. 2015, 169, 530-548. [CrossRef] [PubMed]

62. Bent, A.F.; Clough, S.J. Agrobacterium germ-line transformation: Transformation of Arabidopsis without tissue culture. In Plant Molecular Biology Manual; Springer: Dordrecht, The Netherlands, 1998; pp. 17-30.

63. Han, Y.S.; Wang, W.; Sun, J.; Ding, M.Q.; Zhao, R.; Deng, S.R.; Wang, F.F.; Hu, Y.; Wang, Y.; Lu, Y.J.; et al. Populus euphratica XTH overexpression enhances salinity tolerance by the development of leaf succulence in transgenic tobacco plants. J. Exp. Bot. 2013, 64, 4225-4238. [CrossRef] [PubMed]

64. Zhang, Y.N.; Wang, Y.; Gang, S.; Zhang, Y.H.; Deng, J.Y.; Deng, S.R.; Wang, M.J.; Zhang, H.L.; Yao, J.; Ma, X.J.; et al. Populus euphratica $\mathrm{J} 3$ mediates root $\mathrm{K}^{+} / \mathrm{Na}^{+}$homeostasis by activating plasma membrane $\mathrm{H}^{+}$-ATPase in transgenic Arabidopsis under $\mathrm{NaCl}$ salinity. Plant Cell Tissue Organ Cult. 2017, 131, 75-88. [CrossRef]

65. Livak, K.J.; Schmittgen, T.D. Analysis of relative gene expression data using real-time quantitative PCR and the $2^{-\Delta \Delta C T}$ Method. Methods 2001, 25, 402-408. [CrossRef] [PubMed]

66. Li, J.; Bao, S.Q.; Zhang, Y.H.; Ma, X.J.; Mishra-Knyrim, M.; Sun, J.; Sa, G.; Shen, X.; Polle, A.; Chen, S.L. Paxillus involutus strains MAJ and NAU mediate $\mathrm{K}^{+} / \mathrm{Na}^{+}$homeostasis in ectomycorrhizal Populus $\times$canescens under sodium chloride stress. Plant Physiol. 2012, 159, 1771-1786. [CrossRef] [PubMed]

67. Lu, Y.J.; Li, N.Y.; Sun, J.; Hou, P.C.; Jing, X.S.; Zhu, H.P.; Deng, S.R.; Han, Y.S.; Huang, X.X.; Ma, X.J.; et al. Exogenous hydrogen peroxide, nitric oxide and calcium mediate root ion fluxes in two non-secretor mangrove species subjected to $\mathrm{NaCl}$ stress. Tree Physiol. 2013, 33, 81-95. [CrossRef] [PubMed]

68. Zhao, N.; Wang, S.J.; Ma, X.J.; Zhu, H.P.; Sa, G.; Sun, J.; Li, N.F.; Zhao, C.J.; Zhao, R.; Chen, S.L. Extracellular ATP mediates cellular $\mathrm{K}^{+} / \mathrm{Na}^{+}$homeostasis in two contrasting poplar species under $\mathrm{NaCl}$ stress. Trees 2016, 30, 825-837. [CrossRef]

69. Bewley, J.D. Lipid peroxidation associated with accelerated aging of Soybean Axes. Plant Physiol. 1980, 65, 245-248.

70. Shen, Z.D.; Ding, M.Q.; Sun, J.; Deng, S.R.; Zhao, R.; Wang, M.J.; Ma, X.J.; Wang, F.F.; Zhang, H.L.; Qian, Z.Y.; et al. Overexpression of PeHSF mediates leaf ROS homeostasis in transgenic tobacco lines grown under salt stress conditions. Plant Cell Tissue Organ Cult. 2013, 115, 299-308. [CrossRef]

71. Patra, H.K.; Kar, M.; Mishra, D. Catalase activity in leaves and cotyledons during plant development and senescence. Biochem. Physiol. Pflanz. 1978, 4, 385-390. [CrossRef]

72. Maehly, A.; Chance, B. The assay catalases and peroxidases. Methods Biochem. Anal. 1954, 1, 357-424. [PubMed]

(C) 2019 by the authors. Licensee MDPI, Basel, Switzerland. This article is an open access article distributed under the terms and conditions of the Creative Commons Attribution (CC BY) license (http://creativecommons.org/licenses/by/4.0/). 